
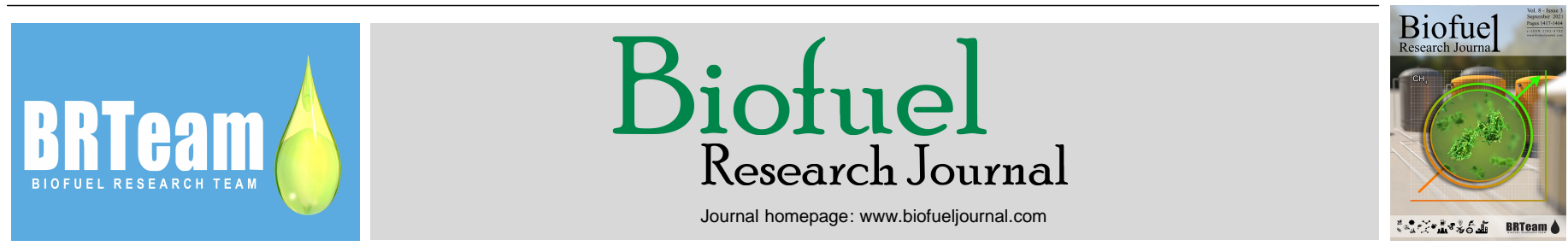

Original Research Paper

\title{
Combining pieces: a thorough analysis of light activation boosting power and co-substrate preferences for the catalytic efficiency of lytic polysaccharide monooxygenase MtLPMO9A
}

\author{
Ana Gabriela V. Sepulchro ${ }^{1}$, Vanessa O.A. Pellegrini ${ }^{1}$, Lucas D. Dias ${ }^{1}$, Marco A.S. Kadowaki ${ }^{2}$, David Cannella ${ }^{2}$, Igor \\ Polikarpov $^{1, *}$
}

${ }^{I}$ Instituto de Física de São Carlos, Universidade de São Paulo, Avenida Trabalhador São-carlense 400, 13566-590 São Carlos, SP, Brasil.

${ }^{2}$ PhotoBioCatalysis Unit - BioCat, CPBL and BTL departments, Interfaculty School of Bioengineers, Université libre de Bruxelles, Campus de la Plaine, Bd.

du Triomphe, Acc.2, CP 245, 1050 Bruxelles, Belgium.

\section{HIGHLIGHTS}

$>M t$ LPMO9A can be efficiently activated by light at the presence of chlorophyllin.

$>$ Photoactivation improves performance of MtLPMO9A on crystalline cellulose.

$>$ MtLPMO9A can use both $\mathrm{O}_{2}$ and $\mathrm{H}_{2} \mathrm{O}_{2}$ as co-

substrates.

$>$ For $\mathrm{H}_{2} \mathrm{O}_{2}$ reactions $M t L P M O 9 A$ requires

chemical reductant.

$>$ Photobiocatalysis mediated by LPMOs might

play a role in plant biomass valorization.

\section{GRAPHICAL ABSTRACT}

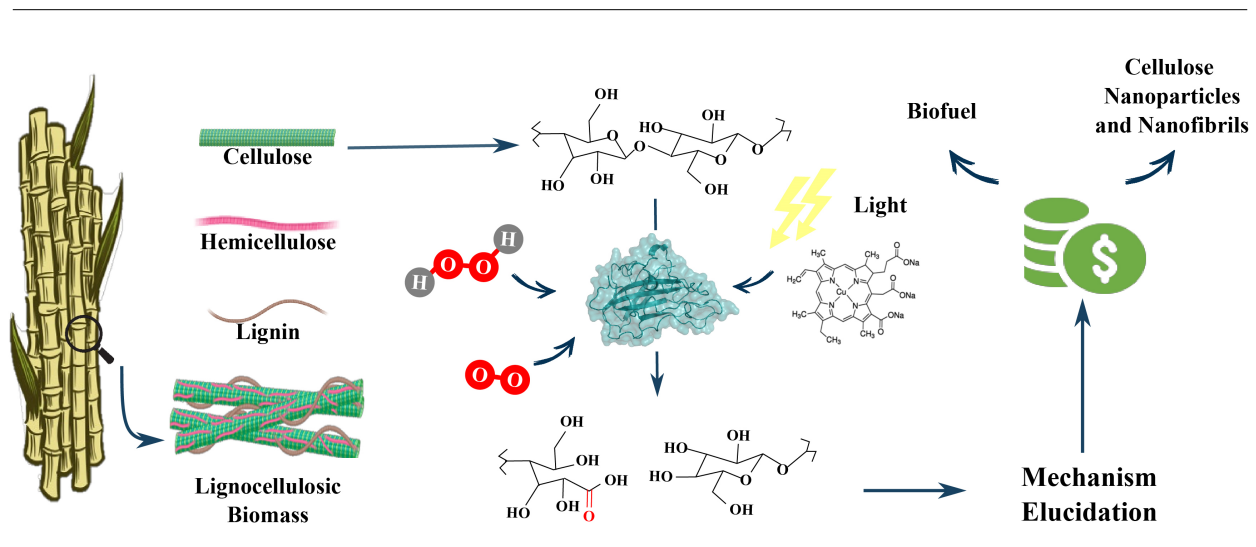

\section{ARTICLE INFO}

\section{Article history:}

Received 1 May 2021

Received in revised form 14 August 2021

Accepted 17 August 2021

Available online 1 September 2021

\section{Keywords:}

Lytic polysaccharide monooxygenases

Chlorophyllin

Light

Co-substrates utilization

Biomass conversion

\begin{abstract}
Cost-efficient plant biomass conversion using biochemical and/or chemical routes is essential for transitioning to sustainable chemical technologies and renewable biofuels. Lytic polysaccharide monooxygenases (LPMOs) are copper-dependent enzymes that make part of modern hydrolytic cocktails destined for plant biomass degradation. Here, we characterized $M t$ LPMO9A from Thermothelomyces thermophilus M77 (formerly Myceliophthora thermophila) and demonstrated that it could be efficiently driven by chlorophyllin excited by light in the presence of a reductant agent. However, in the absence of chemical reductant, chlorophyllin and light alone do not lead to a significant release of the reaction products by the LPMO, indicating a low capacity of $M t$ LPMO9A reduction (either via direct electron transfer or via superoxide ion, $\mathrm{O}_{2}{ }^{-}$). We showed that photocatalysis could significantly increase the LPMO activity against highly crystalline and recalcitrant cellulosic substrates, which are poorly degraded in the absence of chlorophyllin and light. We also evaluated the use of co-substrates by $M t$ LPMO9A, revealing that the enzyme can use both hydrogen peroxide $\left(\mathrm{H}_{2} \mathrm{O}_{2}\right)$ and molecular oxygen $\left(\mathrm{O}_{2}\right)$ as co-substrates for cellulose catalytic oxidation.
\end{abstract}




\section{Contents}

1. Introduction.

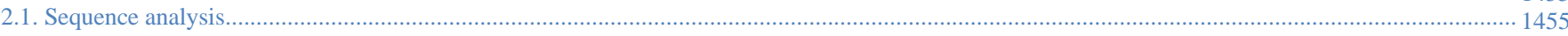

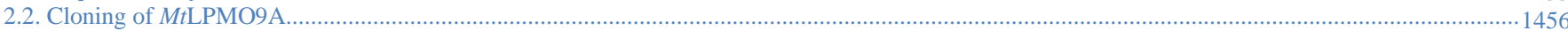

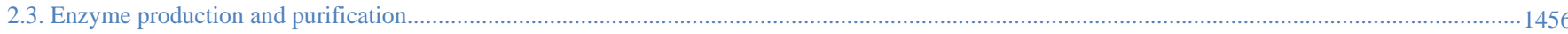

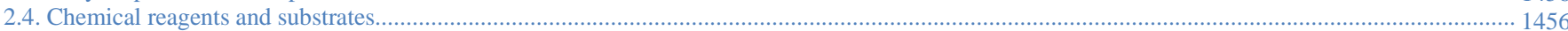

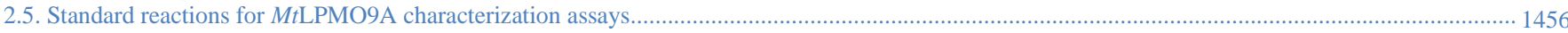

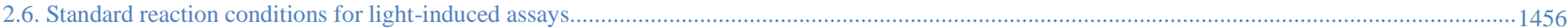

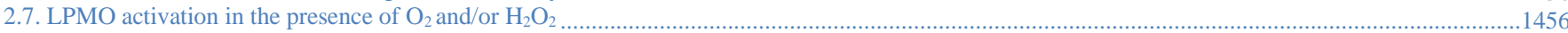

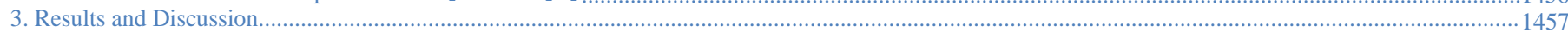

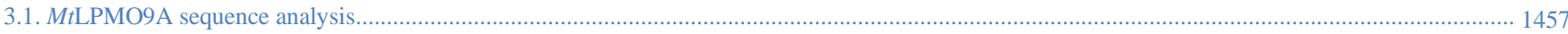

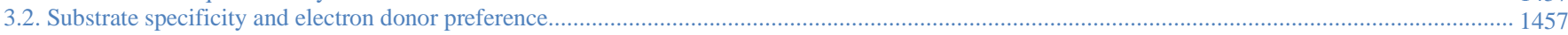

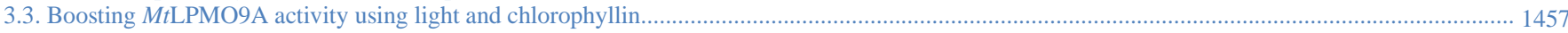

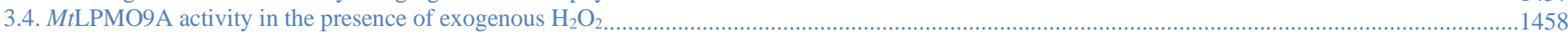

4. Practical implications of the present study ………

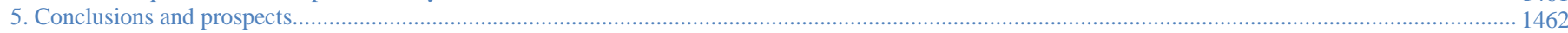

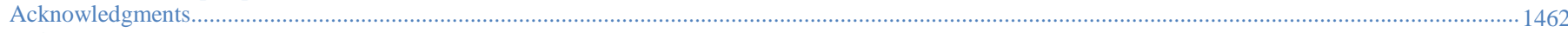

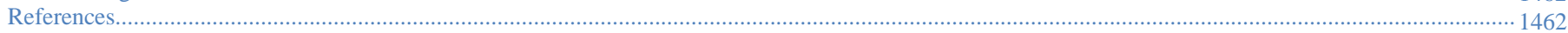

\begin{tabular}{|ll|}
\hline Abbreviations & \\
AA & Auxiliary activity \\
AscA & Ascorbic acid \\
CAZy & Carbohydrate-active enzymes \\
Chl & Chlorophyllin \\
DNS & Dinitrosalicylic acid \\
GallA & Gallic acid \\
GHs & Glycosyl hydrolases \\
HPAEC & High-performance anion exchange chromatography \\
L-cys & L-cysteine \\
LPMOs & Lytic polysaccharide monooxygenases \\
NCBI & National Center for Biotechnology Information \\
PASC & Phosphoric acid swollen cellulose \\
PDB & Protein data bank \\
PyrA & Pyrogallic acid \\
QM/MM & Quantum mechanics/molecular mechanics \\
\hline
\end{tabular}

\section{Introduction}

Enzymatic biocatalysis of renewable lignocellulosic biomass is a key solution for circular economy and mitigation of growing environmental impacts (Pothiraj et al., 2006; Ragauskas et al., 2006). However, the high recalcitrance of plant biopolymers makes their bioconversion a non-trivial task. Several biotechnological solutions aimed to overcome this problem are based on the use of enzymes capable of acting synergistically for the efficient degradation of carbohydrate polymers (Himmel et al., 2007; Steen et al., 2010).

In this context, lytic polysaccharide monooxygenases (LPMOs) have emerged as auxiliary activity (AA) enzymes facilitating the degradation of plant polysaccharides by glycosyl hydrolases (GHs). The potential of LPMOs in accelerating the enzymatic hydrolysis of lignocellulosic biomass was first reported in 2010 (Harris et al., 2010). In the same year, Vaaje-Kolstad et al. (2010) revealed that LPMOs catalyze the oxidative cleavage of glycosidic bonds. Since then, LPMOs have been extensively investigated and, due to their ability to boost activities of cellulases in recalcitrant plant biomass degradation, they have become crucial components of the commercial enzymatic cocktails used in modern biorefineries (Harris et al., 2010; Horn et al., 2012; Müller et al., 2015).

It was initially proposed that LPMOs enhance cellulase activities by introducing catalytic nicks in the polysaccharide chains of crystalline substrates, thus creating access points for cellulases (Vermaas et al., 2015; Eibinger et al., 2017; Song et al., 2018). However, recent studies demonstrated that the interactions between LPMOs and cellulases are much more complex than initially thought and can depend on several factors such as the regioselectivity of LPMO, the type of substrate, and the particular carbohydrate-active enzymes (CAZy) family the cellulase belongs to (Eibinger et al., 2014; Keller et al., 2020a).

LPMO activities and their reaction mechanism have been actively investigated over the last decade and involve reducing the active site copper by an external agent (Quinlan et al., 2011; Aachmann et al., 2012). The enzymes proceed using either $\mathrm{O}_{2}$ (Vaaje-Kolstad et al., 2010; Beeson et al. 2012) or $\mathrm{H}_{2} \mathrm{O}_{2}$ (Bissaro et al., 2017; Hangasky et al., 2018; Kuusk et al., 2019) as co-substrates to oxidize chains of cellulose (and/or other biopolymers). There is also apparent promiscuity for this class of enzymes concerning the origin of the electron donor. Although chemical reductants such as ascorbic acid are the most commonly used (Vaaje-Kolstad et al., 2010; Beeson et al., 2012; Agger et al., 2014; Frommhagen et al., 2015), a number of plant-derived and synthetic reducing agents, as well as several enzymes, have the capacity to reduce the LPMOs (Westereng et al., 2015; Frommhagen et al., 2016; Kracher et al., 2016).

Recently, photopigments-mediated light activation was shown to boost the LPMO activities (Cannella et al., 2016; Bissaro et al., 2016 and 2020; Blossom et al., 2020). Although the scientific community has been actively investigating LPMOs for a decade, photo-induced phenomena were observed only for a handful of LPMOs, including TtLPMO9E (Cannella et al., 2016), TaLPMO9A (Müller et al., 2015), CelS2 (Forsberg et al., 2014), and Cbp21 (Vaaje-Kolstad et al., 2005). Clearly, more examples of photoinduced enzymes should be discovered and characterized to generalize this concept.

Here we set out to identify the co-substrate preferences of Thermothelomyces thermophilus M77 (formerly Myceliophthora thermophila) (MtLPMO9A) and study the influence of different electron donors, including the photo-activated chlorophyllin on its activity. The experiments performed allowed to elucidate the efficiency of $M t$ LPMO9A light-activation mediated by chlorophyllin in different experimental settings. Our results demonstrate that the presence of the reducing agents in the reactions is crucial for efficient photoactivation of $M t L P M O 9 A$ mediated by chlorophyllin. Furthermore, our experiments revealed that the response of the photoactivated system is substrate-dependent, and lightactivated MtLPMO9A has improved enzymatic performance on more crystalline substrates. Finally, the capacity of $M t \mathrm{LPMO} 9 \mathrm{~A}$ to use hydrogen peroxide $\left(\mathrm{H}_{2} \mathrm{O}_{2}\right)$ and molecular oxygen $\left(\mathrm{O}_{2}\right)$ as co-substrates was investigated, contributing to a deeper understanding of the light activation mechanisms and the preferential use of co-substrates for LPMOs in general.

\section{Material and Methods}

\subsection{Sequence analysis}

MtLPMO9A nucleotide and amino acid sequences were analyzed using the NCBI database (National Center for Biotechnology Information) and Protparam to identify the signal peptide, molar mass, and isoelectric point. $M t$ LPMO9A amino acid sequence was also compared with the following 
LPMO9s with protein structures and regioselectivity determined experimentally: AfAA9B (PDBid 5X6A), CvAA9 (PDBid 5NLT), HjAA9A (PDBid 5O2W), HiAA9B (PDBid 2VTC), LsAA9A (PDBid 5ACF), MtAA9D (PDBid 5UFV), $N c$ AA9A (PDBid 5FOH), $N c$ AA9C (PDBid 4D7U), $N c$ AA9F (PDBid 4QI8), NcAA9M (PDBid 4EIS), PcAA9D (PDBid 4B5Q), TaAA9A (PDBid 2YET), and TtAA9E (PDBid 3EII). The structure-based sequence alignment was generated using T-Coffee (Di Tommaso et al., 2011) and ESPript 3.0 (Robert and Gouet, 2014) server (http://espript.ibcp.fr/ESPript/ESPript/). A three-dimensional model of $M t$ LPMO9A was generated using the Swiss-Model Automated Comparative Protein Server (https://swissmodel.expasy.org/) (Biasini et al., 2014) using the crystal structure of $T t \mathrm{LPMO} \mathrm{E}$ from Thielavia terrestris as a template. The figures of $T t \mathrm{LPMO}$ E 3D structure were generated using the PyMOL Molecular Graphics System (Version 1.5.0.4 Schrödinger, LLC, New York, NY, USA)

\subsection{Cloning of MtLPMO9A}

The coding sequence of MtLPMO9A from $T$. thermophilus M77 (MYCTH_85556, UniProt: KP901251) was amplified from genomic DNA, including the native signal peptide using 5'agcatcattacacctcagcaATGCTGACAACAACCTTCGC-3'(forward) and 5'taaatcactagatatctctaTTAGCAACGGAAGACAGCCG-3'(reverse) primers, and cloned into the pEXPYR vector (Gibson et al., 2009; Velasco et al., 2019) using Ligation-Independent Cloning (Camilo and Polikarpov, 2014). The expression plasmid was transformed into Aspergillus nidulans A773 (pyrG89; $w A 3$; pyroA4), and the recombinant strain was selected using the $p y r G$ auxotrophic maker as described earlier (Velasco et al., 2019).

\subsection{Enzyme production and purification}

Recombinant expression of $M t$ LPMO9A was conducted in a static liquid medium. First, A. nidulans MtLPMO9A recombinant strain was activated in a minimal solid medium containing $100 \mathrm{mg} / \mathrm{L}$ of pyridoxine, $50 \mathrm{mg} / \mathrm{L}$ of nitrate salts $\left(120 \mathrm{~g} / \mathrm{L}\right.$ of $\mathrm{NaNO}_{3}, 10.4 \mathrm{~g} / \mathrm{L}$ of $\mathrm{KCl}, 10.4 \mathrm{~g} / \mathrm{L}$ of $\mathrm{MgSO}_{4}$, and $30.4 \mathrm{~g} / \mathrm{L}$ $\left.\mathrm{KH}_{2} \mathrm{PO}_{4}\right), 1 \mathrm{~mL} / \mathrm{L}$ of trace element $\left(22 \mathrm{~g} / \mathrm{L}\right.$ of $\mathrm{ZnSO}_{4}, 11 \mathrm{~g} / \mathrm{L}$ of $\mathrm{H}_{3} \mathrm{BO}_{3}, 5 \mathrm{~g} / \mathrm{L}$ $\mathrm{MnCl}_{2}, 1.6 \mathrm{~g} / \mathrm{L}$ of $\mathrm{CaCl}_{2} .5 \mathrm{H}_{2} \mathrm{O}, 1.6 \mathrm{~g} / \mathrm{L}$ of $\mathrm{CuSO}_{4} .5 \mathrm{H}_{2} \mathrm{O}, 5 \mathrm{~g} / \mathrm{L}$ of $\mathrm{FeSO}_{4} .7 \mathrm{H}_{2} \mathrm{O}$, $1.1 \mathrm{~g} / \mathrm{L}$ of $\mathrm{NaMoO}_{4} \cdot 4 \mathrm{H}_{2} \mathrm{O}$, and $50 \mathrm{~g} / \mathrm{L}$ Na-EDTA), $10 \mathrm{~g} / \mathrm{L}$ of glucose, and 19 $\mathrm{g} / \mathrm{L}$ of agar at $\mathrm{pH} 6.5$.

After $48 \mathrm{~h}$ at $37^{\circ} \mathrm{C}$, the resulting spores (approximately $10^{7}-10^{8}$ spores $/ \mathrm{mL}$ ) were transferred to $0.5 \mathrm{~L}$ induction medium composed of minimum medium supplemented with $50 \mathrm{~g} / \mathrm{L}$ maltose. The heterologous expression was conducted for $40 \mathrm{~h}$ at $37^{\circ} \mathrm{C}$, the mycelial mat was removed, and the culture medium was filtered using Miracloth membranes (Merck KGaA Darmstadt, $\mathrm{DE})$.

The filtrate was collected and centrifuged for $20 \mathrm{~min}, 20,000 \times \mathrm{g}$ at $4{ }^{\circ} \mathrm{C}$. Then the medium was subjected to a second filtration on Miracloth membranes (Merck KGaA Darmstadt, DE) before the concentration step using the Hollow Fiber system (5 kDa cutoff) (GE Healthcare, Chicago, USA) to reduce volume. The protein sample was further purified by $70 \%(\mathrm{w} / \mathrm{v})$ ammonium sulfate precipitation under constant agitation at $10{ }^{\circ} \mathrm{C}$ for $16 \mathrm{~h}$. The sample was centrifuged for $30 \mathrm{~min}, 20,000 \times \mathrm{g}$ at $4^{\circ} \mathrm{C}$ and the pellet resuspended in $10 \mathrm{~mL}$ of $20 \mathrm{mM}$ Tris- $\mathrm{HCl}$ buffer, $\mathrm{pH} 8.0$ and another centrifugation step was performed under the same conditions. The supernatant was subjected to a first purification step in a $5 \mathrm{~mL}$ Q-Sepharose ${ }^{\mathrm{TM}}$ Fast Flow column, where the $M t$ LPMO9A was collected at flow-thought. Then, a hydrophobic interaction chromatography in the HiLoad Phenyl Sepharose 26/10 column (GE Healthcare, Chicago, USA) was performed. Elution was performed with 20 $\mathrm{mM}$ Tris- $\mathrm{HCl}, \mathrm{pH} 8.0$ and $20 \mathrm{mM}$ Tris- $\mathrm{HCl}$ buffers, added to $1 \mathrm{M}\left(\mathrm{NH}_{4}\right)_{2} \mathrm{SO}_{4}$, $\mathrm{pH} 8$.

In the last molecular exclusion chromatography step, MtLPMOA9 was copper-saturated with $\mathrm{CuSO}_{4}$ with a three-fold molar excess and then applied into a HiLoad 16/600 Superdex 75 pg column (GE Healthcare, Chicago, USA) coupled to an Äkta Purifier 10 system. The protein was eluted using an isocratic gradient of $20 \mathrm{mM}$ Tris- $\mathrm{HCl}$ buffer at $\mathrm{pH} 8$ and $150 \mathrm{mM} \mathrm{NaCl}$. Trichoderma harzianum endoglucanase I (Cel7B) was expressed and purified as described previously (Pellegrini et al., 2015).

\subsection{Chemical reagents and substrates}

Electron donors, ascorbic acid (AscA), L-cysteine (L-cys), pyrogallic acid (PyrA), and gallic acid (GallA) (all from Sigma-Aldrich, St. Louis, USA), were diluted in water to a $100 \mathrm{mM}$ stock solution. Chlorophyllin powder (Sigma-Aldrich, St. Louis, USA) was prepared in water in a $50 \mathrm{mM}$ stock solution. All reagent solutions were aliquoted, stored at $-20^{\circ} \mathrm{C}$ in the absence of light and thawed in the dark $10 \mathrm{~min}$ before use. Hydrogen peroxide $\left(\mathrm{H}_{2} \mathrm{O}_{2}\right)$ (Synth, São Paulo, BR) was used in co-substrate studies.

The following substrates were used: phosphoric acid swollen cellulose (PASC) (prepared from Avicel PH-101 (Sigma, Deisenhofen, Germany) as described by Wood (1988)), Avicel (Sigma-Aldrich, St. Louis, USA), labmade bacterial cellulose, and filter paper (Whatman, Maidstone, United Kingdom). To measure the reducing end-groups of saccharides, dinitrosalicylic acid (DNS) was prepared and used as described by Miller (1959).

\subsection{Standard reactions for MtLPMO9A characterization assays}

A typical concentration of $M t$ LPMO9A in the enzymatic reactions was $1 \mu \mathrm{M}$. The enzyme was mixed with $0.3 \%(\mathrm{w} / \mathrm{v})$ of the substrate, as specified for each reaction, in $20 \mathrm{mM}$ of sodium citrate buffer $\mathrm{pH} 5.0$ and $1 \mathrm{mM}$ of the reducing agent, unless stated otherwise. The reactions were conducted at $50{ }^{\circ} \mathrm{C}$ and $1000 \mathrm{rpm}$ for a defined period of time and then analyzed by a high-performance anion exchange chromatography (HPAEC) system (ICS 5000, Dionex, Sunnyvale, USA), equipped with a CarboPacPA1 analytical column $250 \times 2 \mathrm{~mm}$ and precolumn of $50 \times 2 \mathrm{~mm}$ (Dionex, Sunnyvale, USA). Prior to HPAEC analyses, the samples were boiled at $95^{\circ} \mathrm{C}$ for 5 min, centrifuged at $9,600 \times \mathrm{g}$ for $10 \mathrm{~min}$ at $4{ }^{\circ} \mathrm{C}$ and separated from the insoluble substrate by passing through a $0.22 \mu \mathrm{m}$ filter.

Two solutions were used for sample elution: a $100 \mathrm{mM} \mathrm{NaOH}$ (solution A) and a $500 \mathrm{mM}$ sodium acetate plus $100 \mathrm{mM} \mathrm{NaOH}$ (solution B). The flow rate was set to $0.3 \mathrm{~mL} / \mathrm{min}$ at $30^{\circ} \mathrm{C}$. The injection volume was $1 \mu \mathrm{L}$, and the elution was performed using the following steps: isocratic separation (10 $\mathrm{min}, 100 \% \mathrm{~A})$, gradient separation (20 min, $10-100 \% \mathrm{~B})$, column wash ( $8 \mathrm{~min}, 100 \% \mathrm{~B})$, equilibration $(5 \mathrm{~min}, 100 \% \mathrm{~A})$. Pure cellooligosaccharides (all from Megazymes, Wicklow, Ireland) and oxidized cello-oligosaccharides (prepared as described by Keller et al. (2020b)) were used as the standards for identification and quantification of generated products. To quantify the generated products, $120 \mu \mathrm{L}$ of the soluble product was mixed with $0.1 \mu \mathrm{M}$ of $T$. harzianum endoglucanase I (Cel7B) (Pellegrini et al., 2015) in $20 \mathrm{mM}$ citrate buffer $\mathrm{pH} 5$ followed by overnight incubation at $50{ }^{\circ} \mathrm{C}$. Chromatograms were recorded and analyzed using Chromeleon 7.0 software.

\subsection{Standard reaction conditions for light-induced assays}

To enable light transmission, reactions were performed in a $2 \mathrm{~mL}$ Eppendorf tube (Eppendorf, Hamburg, Germany) sealed with Parafilm ${ }^{R} \mathrm{M}$ (Sigma-Aldrich, St. Louis, USA). Chlorophyllin $(500 \mu \mathrm{M})$ was used in each reaction in sodium phosphate buffer, $\mathrm{pH}$ 6.0. The reactions were initiated by adding the photosensitizer to the reaction followed by light activation using a red-light source, the average photon irradiance in the system was $220.8 \mu \mathrm{mol} / \mathrm{s}\left(22.08 \mathrm{~W} / \mathrm{m}^{2}\right)$. In the experiments conducted in the presence of AscA, its addition was performed simultaneously with the light activation of chlorophyllin.

Chlorophyllin photostability was evaluated by UV-visible spectroscopy at regular time intervals (5 min, $15 \mathrm{~min}, 30 \mathrm{~min}, 1 \mathrm{~h}, 2 \mathrm{~h}, 4 \mathrm{~h}$, and $6 \mathrm{~h}$ ) after the illumination period. The photostability was determined by the exponential fitting of the absorbance peak at $632 \mathrm{~nm}$ as a function of time. UV-vis spectra were obtained on a Cary 5000 UV-Vis-NIR spectrometer at the range of 200 to $800 \mathrm{~nm}$.

\subsection{LPMO activation in the presence of $\mathrm{O}_{2}$ and/or $\mathrm{H}_{2} \mathrm{O}_{2}$}

To determine the use of $\mathrm{H}_{2} \mathrm{O}_{2}$ by $M t L P M O 9 \mathrm{~A}$ as a co-substrate, we first evaluated the enzyme activity under the fixed concentration of $\mathrm{H}_{2} \mathrm{O}_{2}(50$ $\mu \mathrm{M})$ and variable concentrations of AscA $(20 \mu \mathrm{M}, 100 \mu \mathrm{M}, 500 \mu \mathrm{M}$, and 1 $\mathrm{mM}$ ) using 4-h reactions. After determination of the optimum concentration of AscA under these conditions, this concentration was fixed, and the $\mathrm{H}_{2} \mathrm{O}_{2}$ 
concentration was varied as $50 \mu \mathrm{M}, 100 \mu \mathrm{M}, 250 \mu \mathrm{M}$, and $500 \mu \mathrm{M}$, maintaining the same reaction times. This evaluation was performed using PASC $0.3 \%$ $(\mathrm{w} / \mathrm{v})$ and Avicel $1.0 \%(\mathrm{w} / \mathrm{v})$ in $20 \mathrm{mM}$ of sodium citrate buffer at $\mathrm{pH} 5.0$. The optimized conditions for each substrate were evaluated over time, in the presence and the absence of $\mathrm{H}_{2} \mathrm{O}_{2}\left( \pm \mathrm{H}_{2} \mathrm{O}_{2}\right)$.

To measure apparent $\mathrm{H}_{2} \mathrm{O}_{2}$ concentrations, we adopted the previously reported protocol (Kittl et al., 2012) as follows: $50 \mu \mathrm{L}$ of filtrate of the chosen time points were collected and mixed with $50 \mu \mathrm{M}$ Amplex Red reagent and 7.1 $\mathrm{U} / \mathrm{mL}$ horseradish peroxidase (both from Sigma-Aldrich) in $100 \mathrm{mM}$ of sodium phosphate buffer $\mathrm{pH} 6.0$ to reach $100 \mu \mathrm{L}$ of the final volume. The reaction was incubated at $30^{\circ} \mathrm{C}$ in a spectrophotometer, and its absorbance was measured at $563 \mathrm{~nm}$.

Finally, the role of $\mathrm{O}_{2}$ and/or $\mathrm{H}_{2} \mathrm{O}_{2}$ as a co-substrate was evaluated under $\mathrm{N}_{2}$ atmosphere, using PASC and Avicel as substrates. To confirm that the enzymatic reactions were performed under low oxygen tension, we measured the $\mathrm{O}_{2}$ pressure in liquid using the NeoFox optical oxygen sensor (OceanOptics). When present, $\mathrm{H}_{2} \mathrm{O}_{2}$ was added in a $50 \mu \mathrm{M}$ final concentration. These reactions were performed for $30 \mathrm{~min}$ and were all performed in duplicates.

\section{Results and Discussion}

\subsection{MtLPMO9A sequence analysis}

The gene sequence of $M t \mathrm{LPMO} 9 \mathrm{~A}$ is $749 \mathrm{bp}$ in length, including a putative $71 \mathrm{bp}$ intron (395-465 bp). Interestingly, MtLPMO9A is found in the same genomic context and in-frame with another LPMO MtLPMO9T (MYCTH_2311323) and the cellobiose dehydrogenase $M t \mathrm{CDH}$ (MYCTH 58125), indicating possible evolutionary pressure. The mature $M t$ LPMO9A contains 208 residues after post-translational processing of the signal peptide (residues 1-17, VSA-HY), releasing the crucial N-terminal histidine 1. Moreover, no additional domains, such as carbohydrate-binding modules (CBM) sometimes found at the C-terminal part of LPMOs, were identified. The enzyme molecular mass of $22,775 \mathrm{Da}$ and isoelectric point ( $\mathrm{pI}$ ) of 6.6 was predicted based on the amino acid sequence. Low glycosylation of $M t$ LPMO9A was expected since just one putative $O$-glycosylation site (at residue S170) was detected by the bioinformatics tools NetNGlyc and NetOGlyc. BLAST (NCBI) analysis showed the highest sequence identity of 86\% shared with the uncharacterized CHGG_08275 from Chaetomium globosum and $>75 \%$ with the C1 specific NcLPMO9F (NCU03328) from Neurospora crassa and the C1/C4 specific TtLPMO9E (THITE_2122979) from Thielavia terrestris. The latter two AA9 family LPMOs have their tridimensional structures deposited to the Protein Data Bank (PDB), thus allowing to build $M t$ LPMO9A homology model. The copper-coordinating residues His1, His68, and Tyr153, essential for oxidative activity, are conserved in the MtLPMO9A structure (Fig. 1). Moreover, a structural-guided multiple sequence alignment of $M t$ LPMO9A with fifteen well-known LPMO9s indicated a putative $\mathrm{C} 1$-regioselectivity based on the highest identity criteria. This comparison also revealed an absence of L3-loop, the major structural feature differentiating $\mathrm{C} 1$ and C4-specific LPMO9s, such as NcLPMO9A, $N c$ LPMO9C, and $N c$ LPMOD (Fig. 1a).

\subsection{Substrate specificity and electron donor preference}

MtLPMO9A activity was evaluated using PASC, Avicel, filter paper, and bacterial cellulose as cellulosic substrates in 16-h reactions. Under tested conditions, MtLPMO9A activity was highest against PASC (Fig. 2a). This selectivity may be due to the higher accessibility of the latter substrate, which facilitates its oxidative cleavage by the enzyme. MtLPMO9A generated both C1- and C4- oxidized cellopyranose residues. Undoubtedly, there is a clear preference for oxidation at the $\mathrm{C} 1$ position. Still, a minor fraction of $\mathrm{C} 4$ oxidised products and also $\mathrm{C} 1 / \mathrm{C} 4$ oxidized celooligossacharides were observed (Fig. 2a).

The selectivity of MtLPMO9A for different reducing agents was also evaluated in a 16-h reaction using ascorbic acid, pyrogallic acid, gallic acid, and L-cysteine (Fig. 2b). These chemical electron donors can be classified into three distinct groups based on the structural similarities of their functional groups (Frommhagen et al., 2016). Gallic and pyrogallic acid comprise a group of compounds with a 1,2,3-benzenetriol moiety. L-cysteine belongs to a group of sulfur-containing compounds, and ascorbic acid includes a group of reducing agents with neither a phenolic ring nor a sulfur atom.

Among the analyzed compounds, gallic acid promoted the weakest activation of $M t L P M O 9 A$. Ascorbic acid was responsible for the strongest LPMO activation, followed by pyrogallic acid and L-cysteine (Fig. 2b). Ascorbic acid is being extensively used in LPMO studies (Vaaje-Kolstad et al., 2010; Phillips et al., 2011; Beeson et al., 2012; Isaksen et al., 2014; Vu et al., 2014; Velasco et al., 2021), although recent studies revealed that ascorbate-driven LPMO reactions are highly sensitive to very low amounts of free copper (Stepnov et al., 2021). Furthermore, molecular dynamic simulations using the quantum mechanics/molecular mechanics (QM/MM) method have demonstrated that ascorbate rapidly reduces LPMO-Cu(II) in a thermodynamically favorable process (Wang et al., 2019; Wang et al. 2020). Furthermore, the same simulations indicated that the electron transfer in this system is mediated by water molecules, thus potentially relieving the requirement of ascorbate to bind the LPMO to accomplish copper reduction (Wang et al., 2019 and 2020).

\subsection{Boosting MtLPMO9A activity using light and chlorophyllin}

To assess the ability of light-activated systems to activate MtLPMO9A, we used chlorophyllin as a light-harvesting molecule (Cannella et al., 2016; Bissaro et al., 2020; Blossom et al., 2020). Figure 3a shows the efficiency of the photoactivation system, leading to the strong stimulation of $M t$ LPMO9A activity.

However, evaluation for longer reaction times showed that the photoactivated coupled system led to a product-release saturation faster than the ascorbic acid-driven reaction, indicating an early inactivation of the enzyme under conditions of photoactivation (Fig. 3b). This phenomenon is more probably a result of $\mathrm{H}_{2} \mathrm{O}_{2}$ formation in the photoactivation process, which, at high concentrations, leads to MtLPMO9A inactivation (Bissaro et al., 2020). Nevertheless, MtLPMO9A under the photoactivation conditions shows highly efficient product release at short reaction times. When the photoactivated system (MtLPMO9A+chlorophyllin+light) was decoupled from the ascorbic acid, the product formation decreased considerably (Fig. 3b). This result is orthogonal to recent observations of Bissaro et al. (2020), and indicates that $M t \mathrm{LPMO} 9 \mathrm{~A}$, in the absence of ascorbic acid, is not as efficiently activated by the $\mathrm{H}_{2} \mathrm{O}_{2}$ produced by light-activated chlorophyllin as the previously studied LPMOs (Bissaro et al., 2020). Since in the absence of chemical reductant, ascorbic acid, LPMO-mediated cellulose oxidation proceeds at a much slower pace, one can conclude that electron donation to the LPMO, either directly by chlorophyllin or via generated superoxide ion, is inefficient for MtLPMO9A (Fig. 3). In the presence of ascorbic acid and molecular oxygen, $M t$ LPMO9A produces considerably higher quantities of oxidized and non-oxidized products (6-h reactions: $636.47 \mu \mathrm{M}$ and 1575.63 $\mu \mathrm{M}$, respectively) as compared to the light-driven reaction mediated by chlorophyllin in the absence of the chemical reductant (6-h reactions: $106.78 \mu \mathrm{M}$ oxidized and $203.95 \mu \mathrm{M}$ non-oxidized) (Fig. 3). A combination of chlorophyllin + light with ascorbic acid in the presence of oxygen results in a significant boost of the LPMO enzymatic activity, followed by rapid inactivation of the enzyme (6-h reactions: $408.12 \mu \mathrm{M}$ oxidized and 555.32 $\mu \mathrm{M}$ non-oxidized), presumably because of its oxidation by the generated reactive oxygen species (Kadowaki et al., 2018).

In parallel with the evaluation of the formation of the products over time, the stability of the chlorophyllin in the photoactivation experiments was monitored (Supplementary Data, Fig. S1). The photosensitizer revealed itself as very stable, as judged by the maintenance of $78.8 \%$ of its initial absorbance after $4 \mathrm{~h}$ of reaction. After $6 \mathrm{~h}$ of reaction, chlorophyllin maintained $67.8 \%$ of its absorbance at the beginning of the reaction, suggesting its considerable stability under applied conditions.

Next, we evaluated whether the presence of light-activated chlorophyllin would stimulate $M t \mathrm{LPMO} 9 \mathrm{~A}$ activity on more recalcitrant substrates. The products generated from Avicel at $1 \%(\mathrm{w} / \mathrm{v})$ were assessed at the end of the 4-h reaction. The presence of light-activated chlorophyllin significantly increased the release of the products by MtLPMO9A, indicating a considerable boost of its activity on the more crystalline substrates (Fig. 4). Thus, in situ $\mathrm{H}_{2} \mathrm{O}_{2}$ production by the photoactivated chlorophyllin (Dolmans et al., 2003; Bissaro et al., 2020) in the presence of chemical 

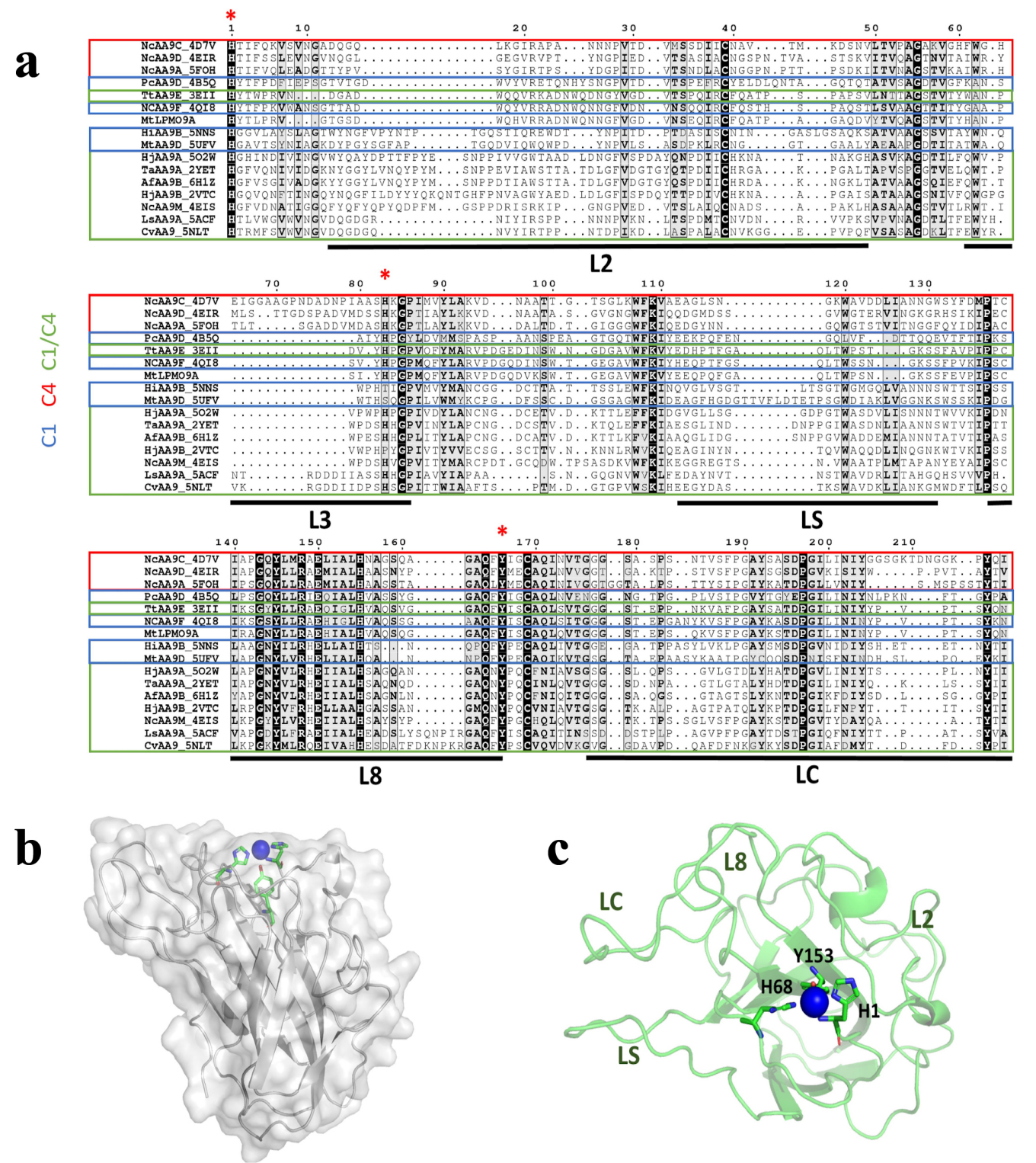

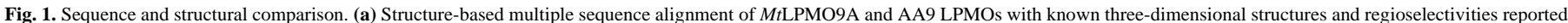

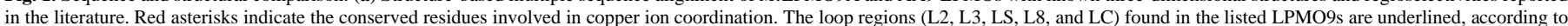

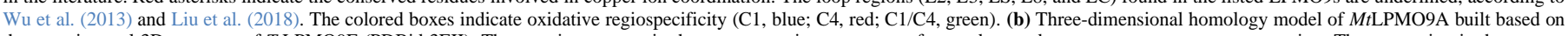

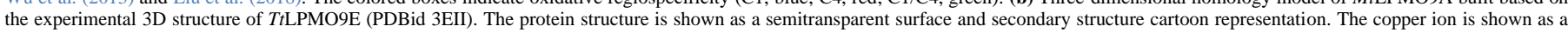
blue sphere. (c) Detailed view of the binding surface highlighting the copper-coordinating residues.

reductant can boost $M t$ LPMO9A activity on the more crystalline and recalcitrant substrates, such as Avicel.

\subsection{MtLPMO9A activity in the presence of exogenous $\mathrm{H}_{2} \mathrm{O}_{2}$}

The LPMO mechanism, with and without the use of photopigments, remains a subject of discussion. Originally, it has been proposed that two external electrons and an $\mathrm{O}_{2}$ molecule were needed for the enzymatic activity (monooxygenase activity) (Phillips et al., 2011; Beeson et al., 2015; Walton and Davies, 2016) whereas, more recently, it has been demonstrated that the enzyme can work as a peroxygenase using $\mathrm{H}_{2} \mathrm{O}_{2}$ molecule as a co-substrate (Bissaro et al., 2017). In the latter case, after the priming reaction, the recruitment of two electrons could become unnecessary (Bissaro et al., 2017).

Recent studies have indicated that both catalytic pathways are possible, unveiling the reaction intermediates in each one (Wang et al., 2019 and 2020).
However, it still remains unclear what can determine the preferential catalytic pathway for a particular LPMO. To analyze the co-substrate preferences of $M t \mathrm{LPMO9A}$, we began by assessing an optimum concentration of the ascorbic acid required for the catalytic process to occur at a fixed concentration of $\mathrm{H}_{2} \mathrm{O}_{2}$.

In the LPMO peroxygenase pathway, the reducing agent could only be necessary for the initial reduction of LPMO-Cu (II) to LPMO-Cu (I) (known as priming), initiating an electronically self-sustaining oxidation process. However, our experimental results demonstrated that the quantity of products generated by $M t \mathrm{LPMO} 9 \mathrm{~A}$ increased with the increasing concentrations of ascorbic acid for both analyzed substrates: PASC (Supplementary Data, Fig. S2a) and Avicel (Fig. S2c).

Then, after setting the ascorbic acid concentration at $1 \mathrm{mM}$, the $\mathrm{H}_{2} \mathrm{O}_{2}$ concentration was varied to study the influence of different concentrations of co-substrate in the reaction medium on the LPMO activity (Figs. S2b 

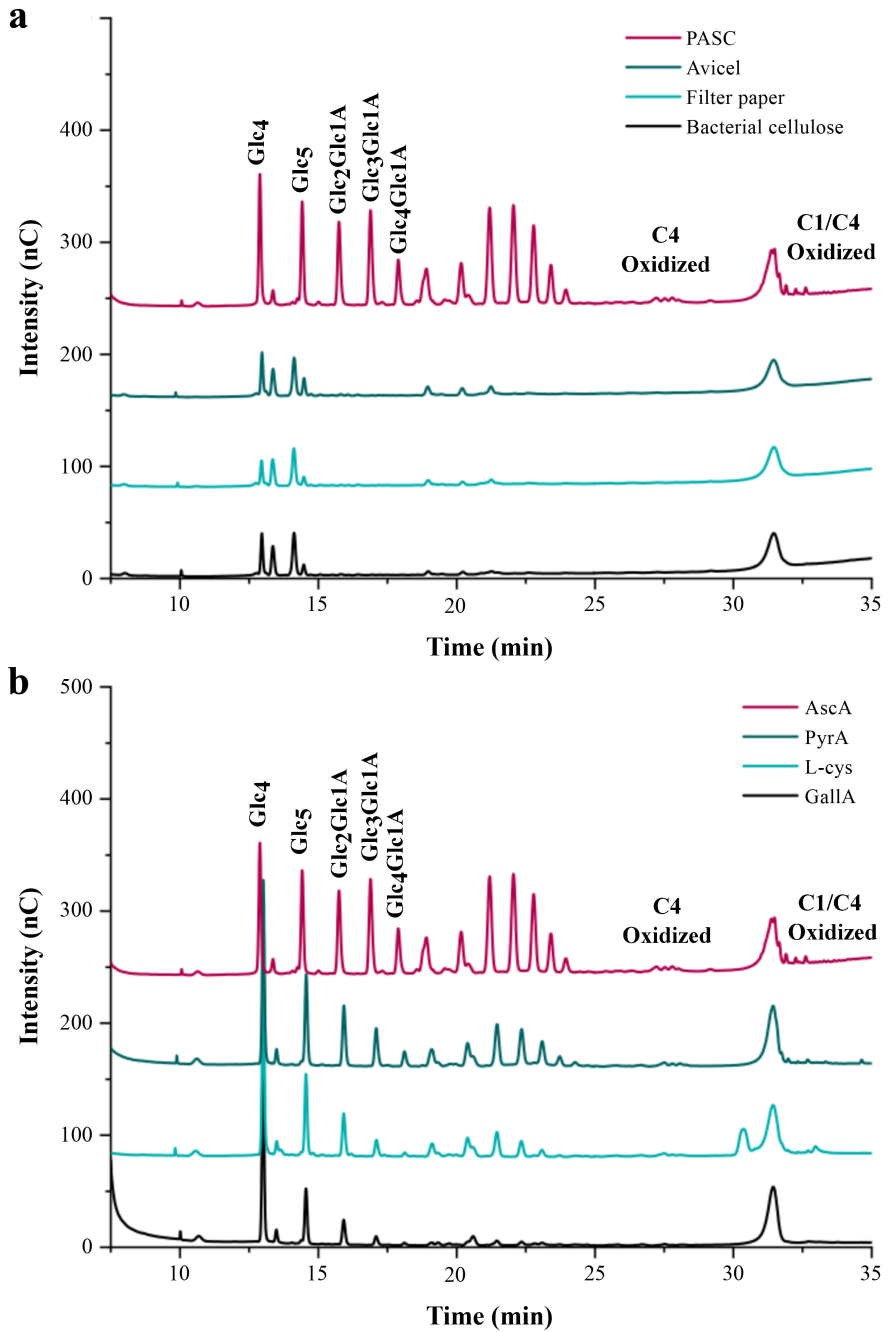

Fig. 2. MtLPMO9A specificity for substrate and electron donor. (a) $M t \mathrm{LPMO9A}(1 \mu \mathrm{M})$ activity in different cellulosic substrates. MtLPMO9A has a clear preference for PASC, a more amorphous and less recalcitrant substrate. (b) Evaluation of the difference in enzymatic activation of different reducing agents, using PASC as a substrate. The highlighted non-oxidized oligosaccharides are Glc4 (cellotetraose) and Glc5 (cellopentaose). C1-oxidized oligosaccharides are GlcGlc1A (cellobionic acid), Glc2Glc1A (cellotrionic acid), Glc3Glc1A (cellotetraonic acid), and Glc4Glc1A (cellopentaonic acid).

and S2d). Once again, products accumulation for both substrates PASC (Fig. S2b) and Avicel (Fig. S2d) had a similar trend, showing a decrease in the release of the products for $\mathrm{H}_{2} \mathrm{O}_{2}$ concentrations higher than $50 \mu \mathrm{M}$, until almost total inactivation of the enzyme by $500 \mu \mathrm{M}$ of $\mathrm{H}_{2} \mathrm{O}_{2}$.

To assess the time course of this process, we quantified the oxidized products over time under determined optimized settings in the absence and the presence of $\mathrm{H}_{2} \mathrm{O}_{2}$. The results of $M t L P M O 9 A$ catalytic activity on PASC and Avicel are given in Figures 5a and 5b, respectively.

$\mathrm{H}_{2} \mathrm{O}_{2}$ addition to MtLPMO9A in the presence of molecular oxygen and ascorbic acid led to an increase in the initial reaction speed, followed by a faster inactivation of the enzyme acting on both PASC (Fig. 5a) and Avicel (Fig. 5b) when compared to the reactions at the absence of hydrogen peroxide. $\mathrm{H}_{2} \mathrm{O}_{2}$ supply led to a decrease in the release of the products on both substrates within time windows longer than $20 \mathrm{~min}$.

To investigate $\mathrm{H}_{2} \mathrm{O}_{2}$ accumulation in the reactions over time, the apparent $\mathrm{H}_{2} \mathrm{O}_{2}$ concentration was measured using Amplex Red reagent and horseradish peroxidase, as described in previously reported protocols (Kittl et al., 2012). When PASC was used as a substrate, it was observed that before the flattening out of the product release presumably caused by the enzyme inactivation, the
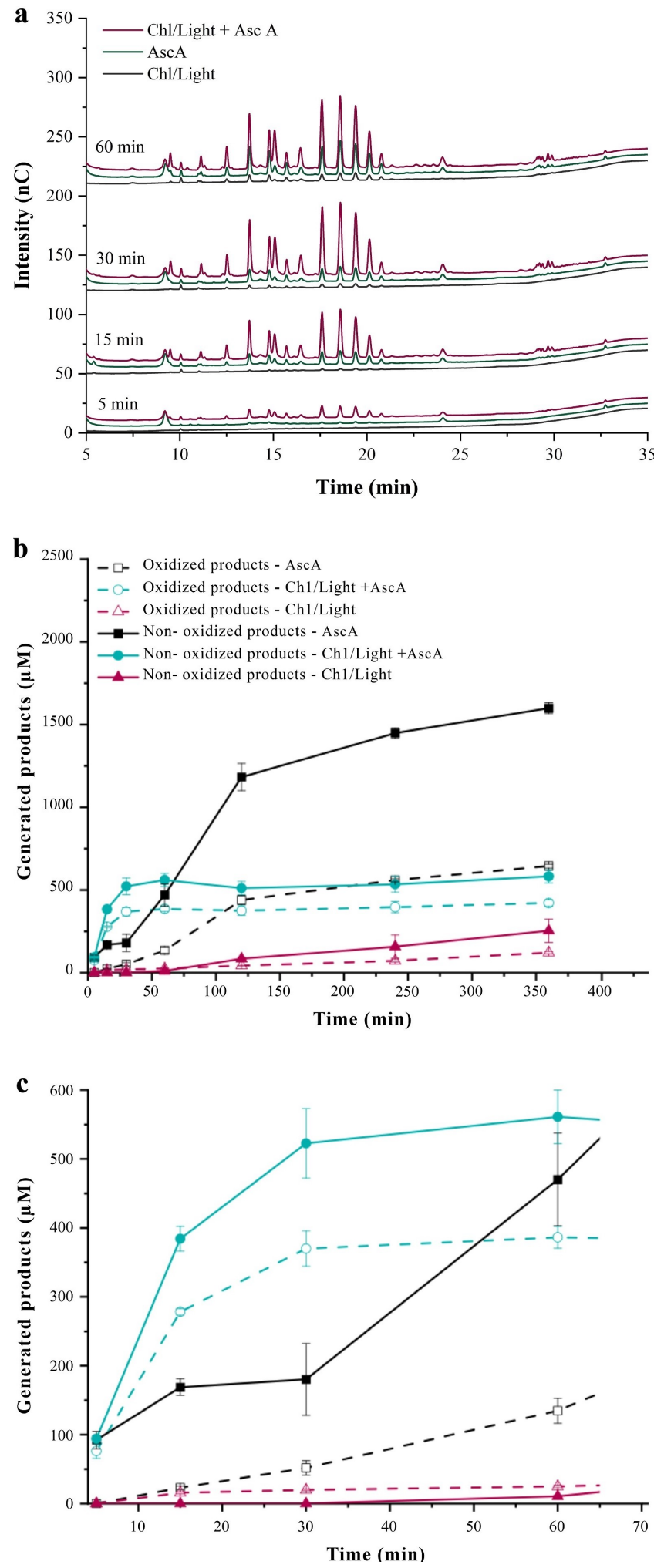

Fig. 3. Evaluation of light boost effect on $M t$ LPMO9A $(1 \mu \mathrm{M})$ activation (a) Chromatograms for 5-, 15-, 30-, and 60-min reactions showing the predominance of products formed at the photoactivated system that couples chlorophyllin and ascorbic acid. (b) Quantitative evaluation of the generated oxidized products as a function of time. (c) Zoom into the curve from the graph in (b) for the reaction times until 60 min. Reactions were performed using PASC as substrate. 


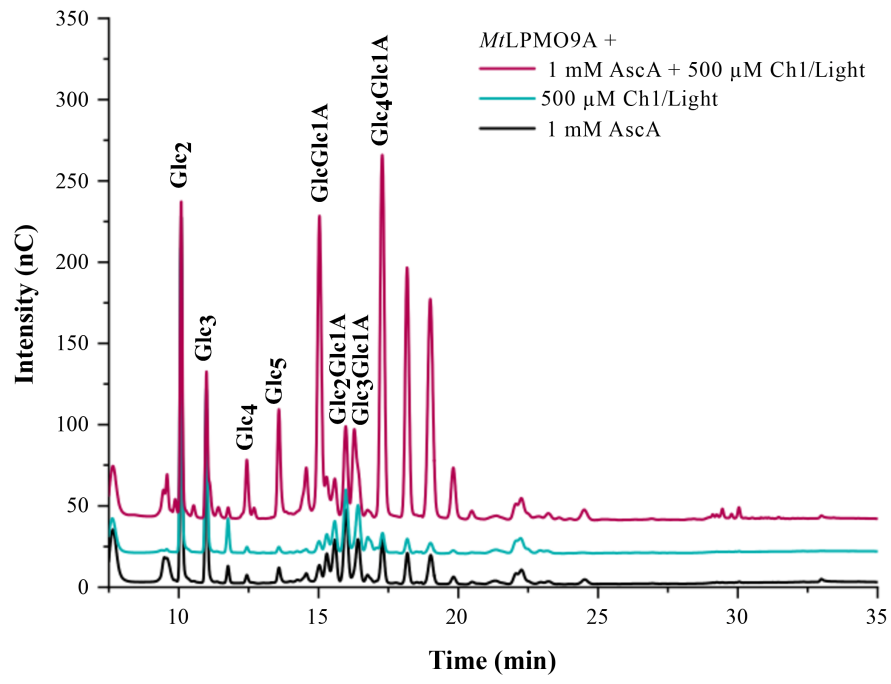

Fig. 4. Change in $M t \mathrm{LPMO} 9 \mathrm{~A}(1 \mu \mathrm{M})$ performance in the presence of light and chlorophyllin. The photoactivated system increased the enzyme's activity on Avicel, a substrate with a higher degree of crystallinity. The marked standards represent, Glc2: cellobiose, Glc3: cellotriose, Glc4: cellotetraose, Glc5: cellopentaose; C1-oxidized oligosaccharides are represented as, GlcGlc1A: cellobionic acid, Glc2Glc1A: cellotrionic acid, Glc3Glc1A: cellotetraonic acid, Glc4Glc1A: cellopentaonic acid.

$\mathrm{H}_{2} \mathrm{O}_{2}$ levels were low and constant, and a peak of $\mathrm{H}_{2} \mathrm{O}_{2}$ was observed shortly after the saturation of the release of the products ( $\mathrm{Fig} .5 \mathrm{c}$ ). Similar behavior was previously observed for different LPMOs by Bissaro et al. (2020).

When Avicel is used as a substrate, apparent $\mathrm{H}_{2} \mathrm{O}_{2}$ concentration in the reaction media is much higher and remains at much higher levels than the reactions with PASC as a substrate. This explains the rapid inactivation of the $M t$ LPMO9A when acting on Avicel. Furthermore, the higher apparent concentrations of $\mathrm{H}_{2} \mathrm{O}_{2}$ are consistent with our previous results, revealing that $M t$ LPMO9A has a smaller activity and presumably lower affinity on more crystalline and recalcitrant Avicel (see Fig. 2). Hence, the generated $\mathrm{H}_{2} \mathrm{O}_{2}$ is not being used by the LPMO for Avicel catalytic oxidation at the same rate as for PASC oxidative cleavage and accumulates in the reaction media (Fig. 5c).

Lastly, we evaluated the commonly used chemical reduction settings (in the presence of only ascorbic acid), the photoactivated reaction system (in the presence of chlorophyllin only), and the coupled photoactivated reaction system (in the presence of chlorophyllin and ascorbic acid) in four different cosubstrate conditions $\left( \pm \mathrm{O}_{2}\right.$ and $\pm \mathrm{H}_{2} \mathrm{O}_{2}$, Figs. 6a-c). All the systems were evaluated with and without oxygen $\left( \pm \mathrm{O}_{2}\right)$ in the presence and absence of the optimal concentration of $\mathrm{H}_{2} \mathrm{O}_{2}(50 \mu \mathrm{M})$ in 30-min reactions $\left( \pm \mathrm{H}_{2} \mathrm{O}_{2}\right)$.

The experiments performed in the presence of $1 \mathrm{mM}$ ascorbic acid in an oxygen-free atmosphere did not lead to the product formation by $M t$ LPMO9A from PASC, demonstrating that presence of co-substrates is essential for the LPMO activity (Fig. 6). The addition of $\mathrm{H}_{2} \mathrm{O}_{2}$ in the oxygen-free environment in the presence of ascorbic acid led to the complete restoration of enzymatic activity of the LPMO. The same occurs in the presence of oxygen and the absence of exogenous $\mathrm{H}_{2} \mathrm{O}_{2}$ (Fig. 6). In other words, in the presence of $1 \mathrm{mM}$ of ascorbic acid, $M t \mathrm{LPMO} 9 \mathrm{~A}$ generated similar amounts of soluble oxidized products when either $\mathrm{O}_{2}$ or $\mathrm{H}_{2} \mathrm{O}_{2}$ were present (Fig. 6). The presence of both $\mathrm{O}_{2}$ and $\mathrm{H}_{2} \mathrm{O}_{2}$ simultaneously generated a profile of soluble products slightly smaller, as already shown in Figure 5, most likely due to inactivation caused by the accumulation of hydrogen peroxide.

Another difference between the three studied reactions is that $M t$ LPMO9A produces a higher amount of non-oxidized products in the presence of $\mathrm{O}_{2}$ and AscA, as compared to the reactions conducted with $\mathrm{H}_{2} \mathrm{O}_{2}$ or $\mathrm{H}_{2} \mathrm{O}_{2}+\mathrm{O}_{2}$ and the same chemical reductant (see Fig. 6a, 5 - 7.5 min elution times).

Next, we evaluated the role of co-substrates $\left(\mathrm{O}_{2}\right.$ and $\left.\mathrm{H}_{2} \mathrm{O}_{2}\right)$ when $M t$ LPMO9A is activated by light in the presence of chlorophyllin. Analysis of chlorophyllin-only photoactivated system (Fig. 6b) shows once again a lack of products formation in the absence of co-substrates $\left(\mathrm{H}_{2} \mathrm{O}_{2}\right.$ and $\left.\mathrm{O}_{2}\right)$ and chemical
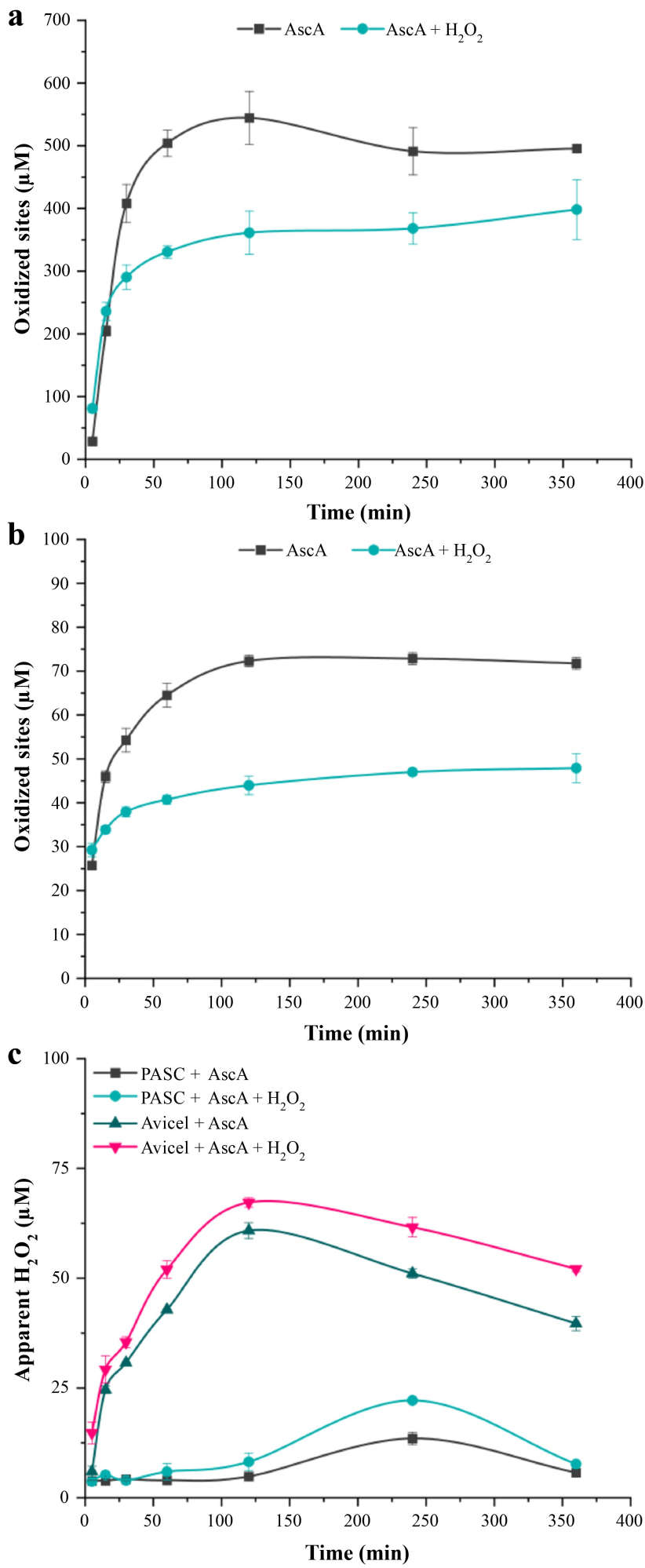

Fig. 5. Evaluation of the co-substrate mechanism of MtLPMO9A. Evaluation of the use of $\mathrm{H}_{2} \mathrm{O}_{2}$ as a co-substrate over time for $M t$ LPMO9A $(1 \mu \mathrm{M})$ using (a) PASC as substrate assessed for the system with only ascorbic acid $(1 \mathrm{mM})$ and the system with ascorbic acid $(1 \mathrm{mM})$ in addition to $\mathrm{H}_{2} \mathrm{O}_{2}(50 \mu \mathrm{M})$; and $(\mathbf{b})$ Avicel as substrate, assessed for the system with only ascorbic acid $(1 \mathrm{mM})$ and the system with ascorbic acid $(1 \mathrm{mM})$ in addition to $\mathrm{H}_{2} \mathrm{O}_{2}(50$ $\mu \mathrm{M})$. (c) The apparent $\mathrm{H}_{2} \mathrm{O}_{2}$ was measured over time for all the reactions using the coupled Amplex Red reagent and horseradish peroxidase reaction. 


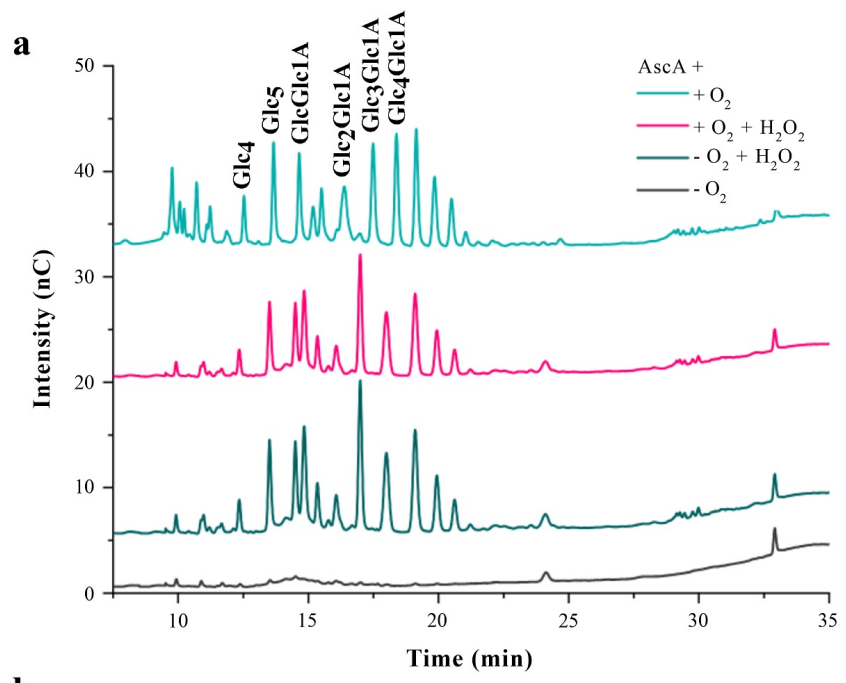

b
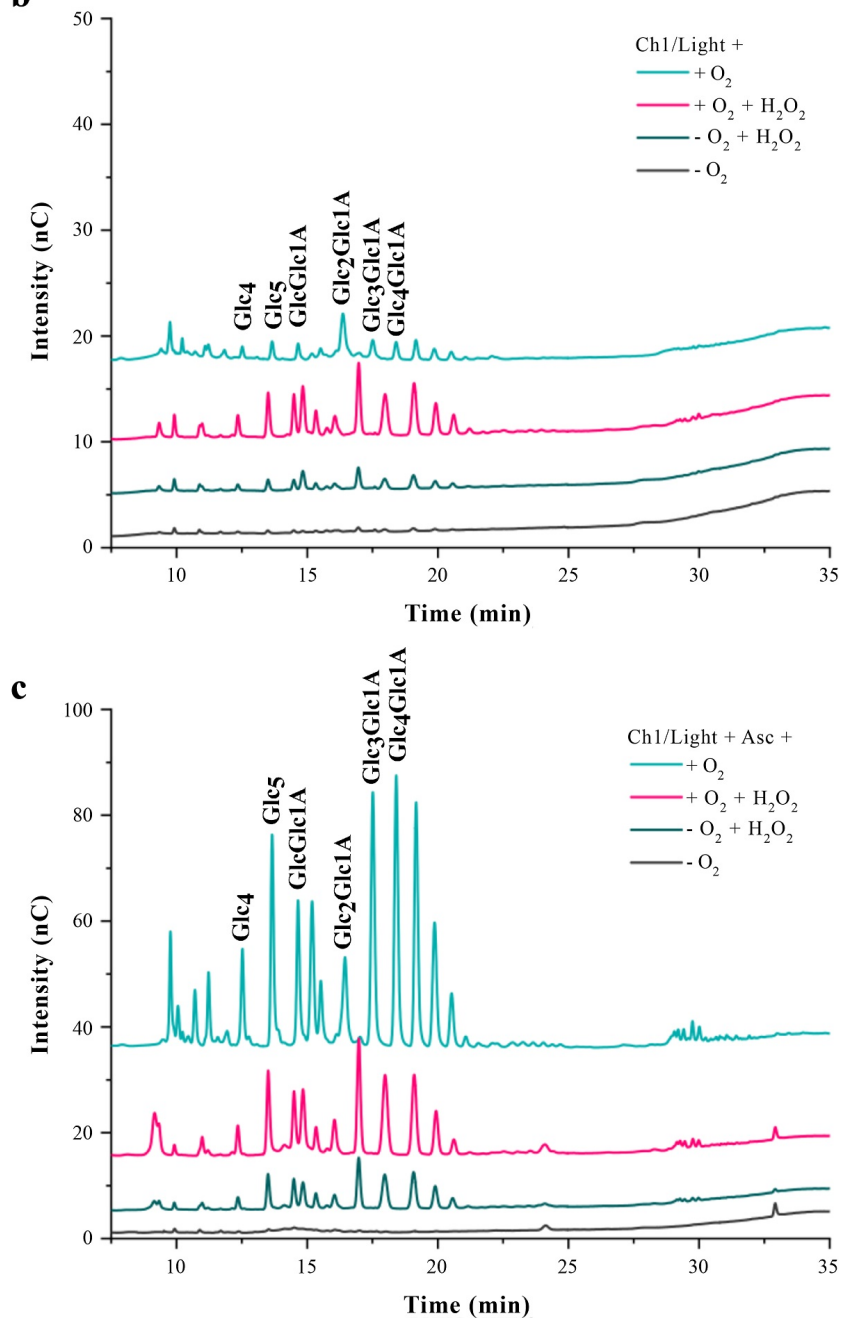

Fig. 6. Evaluation of $M t L P M O 9 A$ activity with and without oxygen and $/ o r \mathrm{H}_{2} \mathrm{O}_{2}$. To evaluate $M t$ LPMO9A $(1 \mu \mathrm{M})$ activity on PASC $\pm \mathrm{O}_{2}$ and $\pm \mathrm{H}_{2} \mathrm{O}_{2}$, the 30-min reactions were evaluated under different settings: (a) using ascorbic acid at $1 \mathrm{mM}$ concentration as a chemical electron donor, (b) photoactivated system with $500 \mu \mathrm{M}$ of chlorophyllin, and (c) coupled photoactivated system that combines $1 \mathrm{mM}$ of ascorbic acid with $500 \mu \mathrm{M}$ of chlorophyllin. The marked standards represent, Glc4: cellotetraose, Glc5: cellopentaose; C1-oxidized oligosaccharides are represented as, GlcGlc1A: cellobionic acid, Glc2Glc1A: cellotrionic acid, Glc3Glc1A: cellotetraonic acid, Glc4Glc1A: cellopentaonic acid. reductant. The presence of either $\mathrm{H}_{2} \mathrm{O}_{2}$ or $\mathrm{O}_{2}$ resulted in a small quantity of products. The simultaneous presence of oxygen and exogenous $\mathrm{H}_{2} \mathrm{O}_{2}$ resulted in a higher amount of soluble products, which, however, was still significantly smaller than that observed in the presence of chemical reductant (AscA; Fig. 6a). The limited catalytic activity of $M t$ LPMO9A in the system with low oxygen tension and exogenous $\mathrm{H}_{2} \mathrm{O}_{2}$ or in the presence of molecular oxygen reveals that chlorophyllin-activation has a low capacity of $M t$ LPMO9A reduction (either via direct electron transfer or via superoxide ion, $\mathrm{O}_{2}^{-}$), an opposite to what was recently shown by Bissaro et al. (2020). The reason for this effect is currently unclear, but the observed differences could be related to different LPMOs that were studied or the variances in the applied experimental conditions. Of note, Bissaro and coworkers used AA10 family bacterial LPMO from Streptomyces coelicolor (ScAA10C) as model cellulolytic enzyme while studying light-driven systems (Bissaro et al., 2020). Neurospora crassa AA9 LPMO (NcAA9F) investigated in the same study performed relatively poorly when driven by light-activated chlorophyllin (Bissaro et al., 2020). This might indicate that structural differences between LPMOs from AA9 and AA10 families can explain observed differences in their chlorophyllin-mediated light activation, which certainly deserved further research.

Finally, we investigated the LPMO activation when chemical reductant (ascorbic acid) was coupled with chlorophyllin (Fig. 6c). Except for a trivial case of a lack of products in the absence of co-substrates $\left(-\mathrm{O}_{2}-\mathrm{H}_{2} \mathrm{O}_{2}\right)$, the results obtained with the photoactivated system, that couples light activation mediated by chlorophyllin and ascorbic acid, are more complex to interpret (Fig. 6c). The quantities of observed reactions products increase from the low oxygen tension system supplied with exogenous $\mathrm{H}_{2} \mathrm{O}_{2}$ ($\mathrm{O}_{2}+\mathrm{H}_{2} \mathrm{O}_{2}$ ) to regular oxygen tension supplied with exogenous $\mathrm{H}_{2} \mathrm{O}_{2}$ $\left(+\mathrm{O}_{2}+\mathrm{H}_{2} \mathrm{O}_{2}\right)$, reaching the maximum at no exogenous $\mathrm{H}_{2} \mathrm{O}_{2}$ and normal oxygen tension condition $\left(+\mathrm{O}_{2}-\mathrm{H}_{2} \mathrm{O}_{2}\right)$ (Fig. 6c).

Since in the presence of AscA, $M t$ LPMO9A is presumably in its reduced form, the first two previously mentioned situations (low oxygen tension system supplied with exogenous $\mathrm{H}_{2} \mathrm{O}_{2}$ and regular oxygen tension supplied with exogenous $\mathrm{H}_{2} \mathrm{O}_{2}$ ) show that $M t \mathrm{LPMO} 9 \mathrm{~A}$ is most probably acting via the peroxygenase pathway. A combination of $\mathrm{O}_{2}$ with light activation via chlorophyllin in the presence of AscA led to the most efficient products formation by $M t$ LPMO9A when compared with the other studied settings. However, the supplementation with $\mathrm{H}_{2} \mathrm{O}_{2}$ suppressed the reaction. This might indicate oxidative inactivation of the LPMO under these experimental conditions (Fig. 6c).

Using more crystalline and recalcitrant Avicel as a substrate for $M t$ LPMO9A activity under the same experimental settings shown in Figure 6 reveals that in the absence of co-substrates $\left(-\mathrm{O}_{2}-\mathrm{H}_{2} \mathrm{O}_{2}\right)$, no significant product formation was observed (Supplementary Data, Fig. S3). When the LPMO was activated only by ascorbic acid, oxygen atmosphere $\left(+\mathrm{O}_{2-}\right.$ $\mathrm{H}_{2} \mathrm{O}_{2}$ ) was the best, to the detriment of the other two studied conditions ($\mathrm{O}_{2}+\mathrm{H}_{2} \mathrm{O}_{2}$ and $+\mathrm{O}_{2}+\mathrm{H}_{2} \mathrm{O}_{2}$, Fig. S3a).

The chlorophyllin-only settings generated very few products, confirming again that the light-activated chlorophyllin alone has a very low capacity of $M t L P M O 9 A$ reduction either via direct electron transfer or via $\mathrm{O}_{2}{ }^{--}$(Fig. S3b). Furthermore, when chlorophyllin in the presence of light was coupled with ascorbic acid, the observed results were more challenging to interpret. In these settings, two of the evaluated conditions showed a high release of products: 1) LPMO under low oxygen tension conditions and in the presence of exogenous $\mathrm{H}_{2} \mathrm{O}_{2}\left(-\mathrm{O}_{2}+\mathrm{H}_{2} \mathrm{O}_{2}\right)$ and 2) LPMO under regular oxygen tension and no exogenous $\mathrm{H}_{2} \mathrm{O}_{2}\left(+\mathrm{O}_{2}-\mathrm{H}_{2} \mathrm{O}_{2}\right)$ (Fig. S3c). However, when both co-substrates were added to the reaction $\left(+\mathrm{O}_{2}+\mathrm{H}_{2} \mathrm{O}_{2}\right)$, there was a strong reduction in the quantity of products, presumably caused by the enzyme self-inactivation (Fig. S3c), further highlighting the importance of a correct balance of co-substrates on the LPMO activity.

\section{Practical implications of the present study}

The results of the present study contribute towards elucidating the mechanisms of LPMO activation and the use of LPMO co-substrates. A deeper understanding of these processes might make it possible to reach optimized conditions for the activity of this class of enzymes within enzymatic mixtures destined for the depolymerization of plant biomass, which is crucial for replacing fossil energy with energy carriers derived from biomass (Tursi, 2019). 
The importance of mechanistic understanding of LPMO-driven catalysis and light activation extrapolates the level of biofuels and could be applied, for example, to the production of cellulose nanoparticles and nanofibrils. These materials, which could be obtained from plant biomass, are eco-friendly and biodegradable and can be used in various areas such as food packaging, biomedicine, electronics, and cosmetics, replacing materials from nonrenewable sources (Rossi et al., 2021). Thus, by better mechanistic understanding and consequent optimization of the LPMOs activities and applications, one can contribute to building bioeconomy and a greener, more sustainable society.

\section{Conclusions and prospects}

LPMOs are an important ancillary activity for enzymatic depolymerization of biomass from lignocellulosic wastes and their conversion into value-added products. The molecular mechanism of LPMO activity is still a subject of debate, and photoactivation of LPMOs was described only for a few of these enzymes. Here, we demonstrated that MtLPMO9A from Thermothelomyces thermophilus could be efficiently activated by light in the presence of chlorophyllin. Under the short reaction times, such a photobiosystem was much more efficient than the chemically activated MtLPMO9A. Furthermore, photoactivation greatly improved the performance of the enzyme on a crystalline substrate, Avicel, on which MtLPMO9A activity is low when only chemical reductant is present in the reaction conditions.

We also evaluated the preferred co-substrate of $M t \mathrm{LPMO} 9 \mathrm{~A}$ and revealed that either $\mathrm{O}_{2}$ or $\mathrm{H}_{2} \mathrm{O}_{2}$ are required for the enzymatic reaction. Furthermore, $M t \mathrm{LPMO}$ A activity was increased by the presence of a chemical reductant (ascorbic acid), indicating that a required direct or indirect electron transfer from photoactivated chlorophyllin to MtLPMO9A is not efficient These results lead to a deeper understanding of the mechanism of action of $M t$ LPMO9A under different reaction conditions.

Present work contributes to new areas of research and investigations mainly concerning the activation mechanism of LPMOs in the presence of different co-substrates in the presence and/or absence of light and photosensitizers.

Future studies of molecular interactions between LPMOs and their substrates are necessary to discover particular characteristics of the enzymes that make them preferentially use particular co-substrate $\left(\mathrm{H}_{2} \mathrm{O}_{2}\right.$ and/or $\left.\mathrm{O}_{2}\right)$ in different experimental settings. Furthermore, physical modifications of the substrates with different recalcitrance, introduced by LPMOs boosted by light in the presence of photopigments, need to be further evaluated.

\section{Acknowledgments}

This research was supported by the Fundação de Amparo à Pesquisa do Estado de São Paulo (FAPESP, grants 2018/22300-0 and 15/13684-0) and by the Conselho Nacional de Desenvolvimento Científico e Tecnológico (CNPq) grants 303988/2016-9 and 134183/2019-3. LDD thanks Fundação de Amparo à Pesquisa do Estado de São Paulo for his post-doctoral grant (2019/13569-8). Also, the Belgian Fonds de la Recherche Scientifique - FNRS supported this work through: MIS-LUX-project F.4502.19 starting grant and PINT-BILATM R.M012.18 to DC; and the Bruselles-Capital Region innovation fund INNOVIRIS - 2019-Bridge-4: Re4Bru project.

\section{References}

[1] Aachmann, F.L., Sørlie, M., Skjåk-bræk, G., Eijsink, V.G., Vaajekolstad, G., 2012. NMR structure of a lytic polysaccharide monooxygenase provides insight into copper binding, protein dynamics, and substrate interactions. Proc. Natl. Acad. Sci. 109(46), 18779-18784.

[2] Agger, J.W., Isaksen, T., Varnai, A., Vidal-Melgosa, S., Willats, W.G., Ludwig, R., Horn, S.J., Eijsink, V.G., Westereng, B., 2014. Discovery of LPMO activity on hemicelluloses shows the importance of oxidative processes in plant cell wall degradation. Proc. Natl. Acad. Sci. 111(17), 6287-6292.

[3] Beeson, W.T., Phillips, C.M., Cate, J.H., Marletta, M.A., 2012. Oxidative cleavage of cellulose by fungal copper-dependent polysaccharide monooxygenases. J. Am. Chem. Soc. 134(2), 890-892

[4] Beeson, W.T., Vu, V.V., Span, E.A., Phillips, C.M., Marletta, M.A., 2015. Cellulose degradation by polysaccharide monooxygenases. Annu. Rev. Biochem. 84, 923-946.
[5] Biasini, M., Bienert, S., Waterhouse, A., Arnold, K., Studer,G., Schmidt, T., Kiefer, F., Cassarino, T.G., Bertoni, M., Bordoli, L., and Schwede, T., 2014. SWISS-MODEL: modelling protein tertiary and quaternary structure using evolutionary information. Nucleic Acids Res. 42(W1), W252-W258.

[6] Bissaro, B., Forsberg, Z., Ni, Y., Hollmann, F., Vaaje-Kolstad, G., Eijsink, V.G., 2016. Fueling biomass-degrading oxidative enzymes by light-driven water oxidation. Green Chem. 18(19), 5357-5366.

[7] Bissaro, B., Kommedal, E., Røhr, A.K., and Eijsink, V.G., 2020 Controlled depolymerization of cellulose by light-driven lytic polysaccharide oxygenases. Nat. Commun. 11(1), 890.

[8] Bissaro, B., Røhr, Å.K., Müller, G., Chylenski, P., Skaugen, M. Forsberg, Z., Horn, S.J., Vaaje-Kolstad, G., Eijsink, V.G., 2017 Oxidative cleavage of polysaccharides by monocopper enzymes depends on $\mathrm{H}_{2} \mathrm{O}_{2}$. Nat. Chem. Biol. 13(10), 1123-1128.

[9] Blossom, B.M., Russo, D.A., Singh, R.K., van Oort, B., Keller, M.B., Simonsen, T.I., Perzon, A., Gamon, L.F., Davies, M.J., Cannella, D. Croce, R., Jensen, P.E., Bjerrum, M.J., Felby, C., 2020 Photobiocatalysis by a lytic polysaccharide monooxygenase using intermittent illumination. ACS Sustainable Chem. Eng. 8(25), 93019310 .

[10] Camilo, C.M. , Polikarpov, I., 2014. High-throughput cloning, expression and purification of glycoside hydrolases using LigationIndependent Cloning (LIC). Protein Expression Purif. 99, 35-42.

[11] Cannella, D., Möllers, K.B., Frigaard, N.U., Jensen, P.E., Bjerrum, M.J., Johansen, K.S., , Felby, C., 2016. Light-driven oxidation of polysaccharides by photosynthetic pigments and a metalloenzyme. Nat. Commun. 7, 11134

[12] Di Tommaso, P., Moretti, S., Xenarios, I., Orobitg, M., Montanyola, A., Chang, J.M., Taly, J.F., Notredame, C. 2011. T-Coffee: a web server for the multiple sequence alignment of protein and RNA sequences using structural information and homology extension. Nucleic Acids Res. 39(suppl-2), W13-W17.

[13] Dolmans, D.E., Fukumura, D., Jain, R.K., 2003. Photodynamic therapy for cancer. Nat. Rev. Cancer. 3(5), 380-387.

[14] Eibinger, M., Ganner, T., Bubner, P., Rošker, S., Kracher, D. Haltrich, D., Ludwig, R., Plank, H., Nidetzky, B., 2014. Cellulose surface degradation by a lytic polysaccharide monooxygenase and it: effect on cellulase hydrolytic efficiency. J. Biol. Chem. 289(52), 35929-35938.

[15] Eibinger, M., Sattelkow, J., Ganner, T., Plank, H., , Nidetzky, B. 2017. Single-molecule study of oxidative enzymatic deconstruction of cellulose. Nat. Commun. 8(1), 894.

[16] Forsberg, Z., Mackenzie, A.K., Sorlie, M., Rohr, A.K., Helland, R. Arvai, A.S., Vaaje-Kolstad, G., Eijsink, V.G., 2014. Structural and functional characterization of a conserved pair of bacterial celluloseoxidizing lytic polysaccharide monooxygenases. Proc. Natl. Acad. Sci. 111(23), 8446-8451.

[17] Frommhagen, M., Koetsier, M.J., Westphal, A.H., Visser, J., Hinz, S.W., Vincken, J.P., van Berkel, W.J., Kabel, M.A., Gruppen, H., 2016. Lytic polysaccharide monooxygenases from Myceliophthora thermophila $\mathrm{C}_{1}$ differ in substrate preference and reducing agent specificity. Biotechnol. Biofuels. 9, 186

[18] Frommhagen, M., Sforza, S., Westphal, A.H., Visser, J., Hinz, S.W., Koetsier, M.J., van Berkel, W.J., Gruppen, H., Kabel, M.A., 2015. Discovery of the combined oxidative cleavage of plant xylan and cellulose by a new fungal polysaccharide monooxygenase. Biotechnol. Biofuels. 8, 101

[19] Gibson, D.G., Young, L., Chuang, R.Y., Venter, J.C., Hutchison, C.A., Smith, H.O., 2009. Enzymatic assembly of DNA molecules up to several hundred kilobases. Nat. Methods. 6(5), 343-345.

[20] Hangasky, J.A., Iavarone, A.T., Marletta, M.A., 2018. Reactivity of $\mathrm{O}_{2}$ versus $\mathrm{H}_{2} \mathrm{O}_{2}$ with polysaccharide monooxygenases. Proc. Natl. Acad. Sci. 115(19), 4915-4920.

[21] Harris, P.V., Welner, D., McFarland, K.C., Re, E., Navarro Poulsen, J.C., Brown, K., Salbo, R., Ding, H., Vlasenko, E., Merino, S., Xu, F., Cherry, J., Larsen, S., Lo Leggio, L., 2010. Stimulation of lignocellulosic biomass hydrolysis by proteins of glycoside hydrolase family 61: structure and function of a large, enigmatic family. Biochemistry. 49(15), 3305-3316. 
[22] Himmel, M.E., Ding, S.Y., Johnson, D.K., Adney, W.S., Nimlos, M.R., Brady, J.W., Foust, T.D., 2007. Biomass recalcitrance: engineering plants and enzymes for biofuels production. Science. 315(5813), 804-807.

[23] Horn, S.J., Vaaje-Kolstad, G., Westereng, B., Eijsink, V., 2012. Novel enzymes for the degradation of cellulose. Biotechnol. Biofuels. 5(1), 45.

[24] Isaksen, T., Westereng, B., Aachmann, F.L., Agger, J.W., Kracher, D., Kittl, R., Ludwig, R., Haltrich, D., Eijsink, V.G., Horn, S.J., 2014. A C4oxidizing lytic polysaccharide monooxygenase cleaving both cellulose and cello-oligosaccharides. J. Biol. Chem. 289(5), 2632-2642.

[25] Kadowaki, M.A., Várnai, A., Jameson, J.K., Leite, A.E.T., Costa-Filho, A.J., Kumagai, P.S., Prade, R.A., Polikarpov, I., Eijsink, V.G., 2018. Functional characterization of a lytic polysaccharide monooxygenase from the thermophilic fungus Myceliophthora thermophila. PLoS One. 13(8), e0202148.

[26] Keller, M.B., Felby, C., Labate, C.A., Pellegrini, V.O.A., Higasi, P., Singh, R.K., Polikarpov, I., Blossom, B.M., 2020a. A simple enzymatic assay for the quantification of $\mathrm{C} 1$-specific cellulose oxidation by lytic polysaccharide monooxygenases. Biotechnol. Lett. 42(1), 93-102.

[27] Keller, M.B., Badino, S.F., Blossom, B.M., McBrayer, B., Borch, K., Westh, P., 2020b. Promoting and impeding effects of lytic polysaccharide monooxygenases on glycoside hydrolase activity. ACS Sustainable Chem. Eng. 8(37), 14117-14126.

[28] Kittl, R., Kracher, D., Burgstaller, D., Haltrich, D., Ludwig, R., 2012. Production of four Neurospora crassa lytic polysaccharide monooxygenases in Pichia pastoris monitored by a fluorimetric assay. Biotechnol. Biofuels. 5, 79.

[29] Kracher, D., Scheiblbrandner, S., Felice, A.K., Breslmayr, E., Preims, M., Ludwicka, K., Haltrich, D., Eijsink, V.G., Ludwig, R., 2016. Extracellular electron transfer systems fuel cellulose oxidative degradation. Science. 352(6289), 1098-1101.

[30] Kuusk, S., Kont, R., Kuusk, P., Heering, A., Sørlie, M., Bissaro, B., Eijsink, V.G., Väljamäe, P., 2019. Kinetic insights into the role of the reductant in $\mathrm{H}_{2} \mathrm{O}_{2}$-driven degradation of chitin by a bacterial lytic polysaccharide monooxygenase. J. Biol. Chem. 294(5), 1516-1528.

[31] Liu, B., Kognole, A.A., Wu, M., Westereng, B., Crowley, M.F., Kim, S., Dimarogona, M., Payne, C.M., Sandgren, M., 2018. Structural and molecular dynamics studies of a C1-oxidizing lytic polysaccharide monooxygenase from Heterobasidion irregulare reveal amino acids important for substrate recognition. FEBS J. 285(12), 2225-2242.

[32] Miller, G.L., 1959. Use of dinitrosalicylic acid reagent for determination of reducing sugar. Anal. Chem. 31(3), 426-428.

[33] Müller, G., Várnai, A., Johansen, K.S., Eijsink, V.G., Horn, S.J., 2015. Harnessing the potential of LPMO-containing cellulase cocktails poses new demands on processing conditions. Biotechnol. Biofuels. 8, 187.

[34] Pellegrini, V.O., Serpa, V.I., Godoy, A.S., Camilo, C.M., Bernardes, A., Rezende, C.A., Junior, N.P., Cairo, J.P.L.F, Squina, F.M., Polikarpov, I., 2015. Recombinant Trichoderma harzianum endoglucanase $\mathrm{I}\left(\mathrm{Cel}_{7} \mathrm{~B}\right)$ is a highly acidic and promiscuous carbohydrate-active enzyme. Appl. Microbiol. Biotechnol. 99(22), 9591-9604.

[35] Phillips, C.M., Beeson IV, W.T., Cate, J.H., Marletta, M.A., 2011. Cellobiose dehydrogenase and a copper-dependent polysaccharide monooxygenase potentiate cellulose degradation by Neurospora crassa. ACS Chem. Biol. 6(12), 1399-1406.

[36] Pothiraj, C., Kanmani, P., Balaji, P., 2006. Bioconversion of lignocellulose materials. Mycobiology. 34(4), 159-165.

[37] Quinlan, R. J., Sweeney, M. D., Lo Leggio, L.L., Otten, H., Poulsen, J.C.N., Johansen, K.S., Krogh, K.B., Jorgensen, C.I., Tovborg, M., Anthonsen, A., Clive T.T, Walter, P., Dupree, P., Xu, F., Davies, G.J., Walton, P.H., 2011. Insights into the oxidative degradation of cellulose by a copper metalloenzyme that exploits biomass components. Proc. Natl. Acad. Sci. 108(37), 15079-15084.

[38] Ragauskas, A.J., Williams, C.K., Davison, B.H., Britovsek, G., Cairney, J., Eckert, C.A., Frederick, W.J., Hallett, J.P., Leak, D.J., Liotta, C.L., Mielenz, J.R., Murphy, R., Templer, R., Tschaplinski, T., 2006. The path forward for biofuels and biomaterials. Science. 311(5760), 484-489

[39] Robert, X., Gouet, P., 2014. Deciphering key features in protein structures with the new endscript server. Nucleic Acids Res. 42(W1), W320-W324.
[40] Rossi, B.R., Pellegrini, V.O., Cortez, A.A., Chiromito, E.M. Carvalho, A.J., Pinto, L.O.,Rezende, C.A., Mastelaro, V.R., Polikarpov, I., 2021. Cellulose nanofibers production using a set of recombinant enzymes. Carbohydr. Polym. 256, 117510

[41] Song, B., Li, B., Wang, X., Shen, W., Park, S., Collings, C., Feng, A., Smith, S.J., Walton, J.D., Ding, S.Y., 2018. Real-time imaging reveals that lytic polysaccharide monooxygenase promotes cellulase activity by increasing cellulose accessibility. Biotechnol. Biofuels. 11,41 .

[42] Steen, E.J., Kang, Y., Bokinsky, G., Hu, Z., Schirmer, A., McClure, A., del Cardayre, S.B., Keasling, J. D., 2010. Microbial production of fatty-acid-derived fuels and chemicals from plant biomass. Nature. 463, 559-562.

[43] Stepnov, A.A., Forsberg, Z., Sørlie, M., Nguyen, G.S., Wentzel, A. Røhr, A.K., Eijsink, V.G., 2021. Unraveling the roles of the reductant and free copper ions in LPMO kinetics. Biotechnol. Biofuels. 14, 28.

[44] Tursi, A., 2019. A review on biomass: importance, chemistry classification, and conversion. Biofuel Res. J. 6(2), 962-979.

[45] Vaaje-Kolstad, G., Horn, S.J., Van Aalten, D.M., Synstad, B., Eijsink, V.G., 2005. The non-catalytic chitin-binding protein CBP21 from Serratia marcescens is Essential for Chitin Degradation* $*$ J Biol. Chem. 280(31), 28492-28497.

[46] Vaaje-Kolstad, G., Westereng, B., Horn, S.J., Liu, Z., Zhai, H., Sørlie, M., Eijsink, V.G., 2010. An oxidative enzyme boosting the enzymatic conversion of recalcitrant polysaccharides. Science. 330(6001), 219 222.

[47] Velasco, J., Oliva, B., Mulinari, E.J., Quintero, L.P., da Silva Lima, A., Gonçalves, A.L., Gonçalves, T.A., Damasio, A., Squina, F.M., Milagres, A.M.F., Abdella, A., Wilkins, M.R., Segato, F., 2019. Heterologous expression and functional characterization of a $\mathrm{GH} 10$ endoxylanase from Aspergillus Fumigatus Var. Niveus with potential biotechnological application. Biotechnol Rep. 24, e00382.

[48] Velasco, J., Pellegrini, V.D.O.A., Sepulchro, A.G.V., Kadowaki, M.A.S., Santo, M.C.E., Polikarpov, I., , Segato, F., 2021. Comparative analysis of two recombinant LPMOs from Aspergillus fumigatus and their effects on sugarcane bagasse saccharification. Enzyme Microb. Technol. 144, 109746

[49] Vermaas, J.V., Crowley, M.F., Beckham, G.T., Payne, C.M., 2015 Effects of lytic polysaccharide monooxygenase oxidation on cellulose structure and binding of oxidized cellulose oligomers to cellulases. J. Phys. Chem. B. 119(20), 6129-6143.

[50] Vu, V.V., Beeson, W.T., Phillips, C.M., Cate, J.H., Marletta, M.A., 2014. Determinants of regioselective hydroxylation in the fungal polysaccharide monooxygenases. J. Am. Chem. Soc. 136(2), 562565.

[51] Walton, P.H., Davies, G.J., 2016. On the catalytic mechanisms of lytic polysaccharide monooxygenases. Curr. Opin. Chem. Biol. 31, 195 207.

[52] Wang, B., Walton, P.H., Rovira, C., 2019. Molecular mechanisms of oxygen activation and hydrogen peroxide formation in lytic polysaccharide monooxygenases. ACS Catal. 9(6), 4958-4969.

[53] Wang, B., Wang, Z., Davies, G.J., Walton, P.H., Rovira, C., 2020 Activation of $\mathrm{O}_{2}$ and $\mathrm{H}_{2} \mathrm{O}_{2}$ by lytic polysaccharide monooxygenases. ACS Catal. 10(21), 12760-12769.

[54] Westereng, B., Cannella, D., Wittrup Agger, J., Jørgensen, H., Larsen Andersen, M., Eijsink, V.G.H., Felby, C., 2015. Enzymatic cellulose oxidation is linked to lignin by long-range electron transfer. Sci. Rep. 5(1), 18561

[55] Wood, T.M., 1988. Preparation of crystalline, amorphous, and dyed cellulase substrates, in: Wood, W.A., Kellogg S.T. (Eds.), Methods in Enzymology. 160. 19-25.

[56] Wu, M., Beckham, G.T., Larsson, A.M., Ishida, T., Kim, S., Payne, C.M., Himmel, M.E., Crowley, M.F., Horn, S.J., Westereng, B., Igarashi, K., Samejima, M., Ståhlberg, J., Eijsink, V.G.H., Sandgren, M. 2013. Crystal Structure and Computational Characterization of the lytic polysaccharide monooxygenase GH61D from the Basidiomycota Fungus Phanerochaete chrysosporium. J. Biol. Chem. 288(18), 12828-12839. 


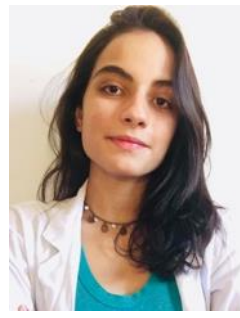

Ana Gabriela Veiga Sepulchro, M.Sc., is a molecular biologist and biophysicist. Her research has been focused on the study of CAZymes aiming at the development of economically viable and sustainable biotechnologies applied to second-generation ethanol production. Her research interests also include development of sustainable lifestyles and improvement of the efficiencies of processes that can contribute to the green transition of our societies. Her research profile on Google Scholar can be found at:

https://scholar.google.com.br/citations? user=jEGGrqcAAAAJ\&hl=pt-

BR\&oi=ao.

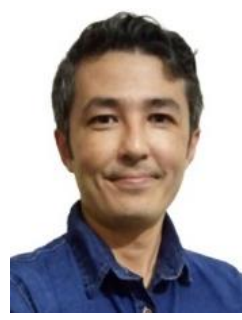

Marco Antonio Seiki Kadowaki, Ph.D., is a Senior PostDoc Researcher at the Université Libre de Bruxelles (ULB), Belgium. He has a Ph.D. degree and post-doctoral in Molecular and Structural Biology at Federal University of Paraná (UFPR) and University of São Paulo (USP, Brazil). He has published over 31 peer-reviewed journal papers with an h-index of 12 . His research interests include (1) structural dynamics and molecular mechanisms of lytic polysaccharide monooxygenases; (2) PhotoBioCatalysis in biomass degradation; and (3) high-throughput methods in the expression and characterization of oxidative enzymes. His Google Scholar profile can be found at: https://scholar.google.com.br/citations?user=nkakSVwAAAAJ\&hl=pt-BR.

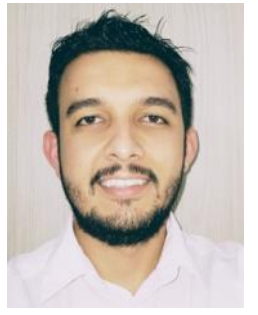

Lucas D. Dias, Ph.D., received his Ph.D. in Chemistry at the University of Coimbra (Portugal), and he is currently a postdoctoral research fellow at the University of São Paulo (USP, Brazil). His current research interests include fields of Medical Physics and Catalysis, namely mechanisms in Photodynamic Therapy, synthesis of photosensitizers for Photodynamic Therapy, design, synthesis, and application of photocatalysts, and synthesis of homogeneous and immobilized catalysts based on tetrapyrrolic macrocycles for the activation of small molecules $\left(\mathrm{O}_{2}, \mathrm{CO}\right.$, and $\mathrm{CO}_{2}$ ). He has published 37 peer-reviewed papers in national/international journals so far and is an author of more than 45 communications (oral and posters) at national/international scientific meetings. He is also an inventor of 2 patents.

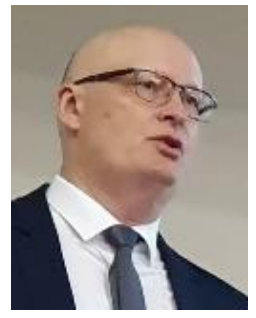

Igor Polikarpov is a Full Professor of the Sao Carlos Institute of Physics, University of São Paulo. His main scientific interests are centered at Structural Biology and Molecular Biophysics and their applications in Biotechnology and Biorenewables. He has coordinated joint scientific projects between Brazil and European Union (FP7); Brazil-UK (FAPESP-RCUK); Brazil, Argentina and Uruguay $(\mathrm{CBAB} / \mathrm{CNPq})$, BrazilIndia $(\mathrm{CNPq} / \mathrm{DBT})$, and Brazil- Belgium (FAPESP-FNRS). He is a Commander of the Brazilian National Order of Scientific Merit and a Member of São Paulo State Academy of Sciences. Igor Polikarpov published over 300 scientific papers and his research profile is available at https://orcid.org/0000-0001-9496-4174.

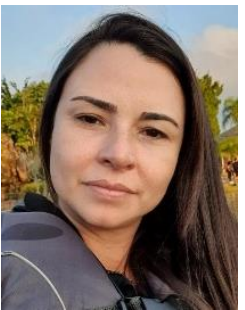

Vanessa de Oliveira Arnoldi Pellegrini, Ph.D., is Biologist with doctorate and post-doctoral experience in molecular biology and biophysics. She has experience in production of enzymes using different expression systems (E. coli, A. nidulans, and $A$. niger). Her research focuses on Cazymes aiming at the improvement of biotechnologies applied not only to second-generation ethanol production but also to production of others green and sustainable products. Her research profile is available at: http://lattes.cnpq.br/8101742882627237 and https://scholar.google.com.br/citations?user=5CdYlaUAAAAJ\&hl=ptBR\&hl=pt-BR.

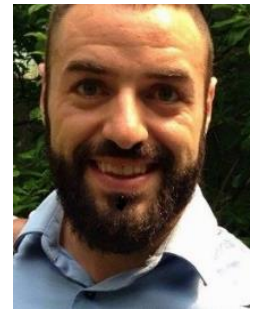

David Cannella, biotechnologist is a junior Associate Professor of the Universite Libre de Bruxelles, leading a cross-border research group: photo-biocatalysis unit. Graduated from $\mathrm{La}$ Sapienza of Rome, obtained a PhD from the University of Copenhagen had focused his research on biomass transformation and biocatalysis, introducing new elements as light's energy and radical stimuli to enhance overall efficiency. His entire research output can be seen here https://scholar.google.com/citations?hl=en\&tzom=-

$120 \& u s e r=5$ WAXw7EAAAAJ\&view_op=list_works\&sortby=pubdate 